\title{
Nanoparticle brain delivery: a guide to verification methods
}

\author{
Robert A Yokel*,1 (iD \\ 1'Department of Pharmaceutical Sciences, University of Kentucky, Lexington, KY 40536-0596, USA \\ *Author for correspondence: Tel.: +1 859257 4855; Fax: +1 859257 7564; ryokel@uky.edu
}

Many reports conclude nanoparticle (NP) brain entry based on bulk brain analysis. Bulk brain includes blood, cerebrospinal fluid and blood vessels within the brain contributing to the blood-brain and blood-cerebrospinal fluid barriers. Considering the brain as neurons, glia and their extracellular space (brain parenchyma), most studies did not show brain parenchymal NP entry. Blood-brain and bloodcerebrospinal fluid barriers anatomy and function are reviewed. Methods demonstrating brain parenchymal NP entry are presented. Results demonstrating bulk brain versus brain parenchymal entry are classified. Studies are reviewed, critiqued and classified to illustrate results demonstrating bulk brain versus parenchymal entry. Brain, blood and peripheral organ NP timecourses are compared and related to brain parenchymal entry evidence suggesting brain NP timecourse informs about brain parenchymal entry.

First draft submitted: 26 April 2019; Accepted for publication: 25 November 2019; Published online: 30 January 2020

Keywords: blood-brain barrier • blood-cerebrospinal fluid barrier • brain parenchyma • capillary depletion • convection-enhanced delivery $\bullet$ in situ brain perfusion $\bullet$ microdialysis $\bullet$ mouse $\bullet$ nanoparticle $\bullet$ rat

\section{The issue addressed in this guide}

When considering nanoparticle (NP) distribution, a question that is often raised is whether they enter the brain. With the goal to use NPs to deliver drugs to the brain, many researchers are hopeful that their NPs do enter the brain. Others are concerned about unintended NP brain entry and potential adverse effects. Many have oversimplified the concept of brain entry. They have not considered the extensive vasculature that permeates the brain, and the potential for an NP to be within the vasculature (blood), associated with components of the blood-brain barrier (BBB) or blood-cerebrospinal fluid barrier (BCSFB), or in cerebrospinal fluid (CSF), rather than in brain parenchyma that houses the brain cells and their extracellular (interstitial) space. This article aims: to inform about the distinction between distribution into the brain (bulk brain) versus brain parenchyma, present methods that can demonstrate brain parenchymal distribution, present a tiered classification of methods and results that demonstrate bulk brain versus brain parenchymal distribution, critically review some reports that claimed brain or brain parenchymal NP distribution and rate them according to the tiered classification, and suggest that NP residence time in the brain often informs about brain parenchymal entry.

\section{BBB anatomy \& function}

To justify the claim that an NP crossed the BBB and entered brain parenchyma requires an understanding of brain anatomy, the vasculature within it and research methods that demonstrate brain parenchymal entry. The primary route to enable NP brain parenchymal entry is across the BBB. The BBB separates the vascular compartment from brain cells that are surrounded by extracellular/interstitial fluid that occupies approximately $20 \%$ of the parenchymal space. The BBB includes brain microvascular endothelial cells (BMECs) that line microvessels within the brain, forming the luminal (blood) side of the BBB (Figure 1). BMECs have efflux transporters that effectively prevent brain parenchymal entry of many substances and metabolic enzymes to maintain brain homeostasis. On the other hand, BMECs have influx transporters that deliver essential nutrients, elements and factors to brain cells from the blood, supporting brain nutrition. Influx transporters have been utilized in a Trojan horse approach to hitchhike NPs through the BBB to brain parenchyma. BMECs differ from endothelial cells that line the vasculature outside of the brain by their near total absence of fenestrations (windows) through which NPs might diffuse and the presence 


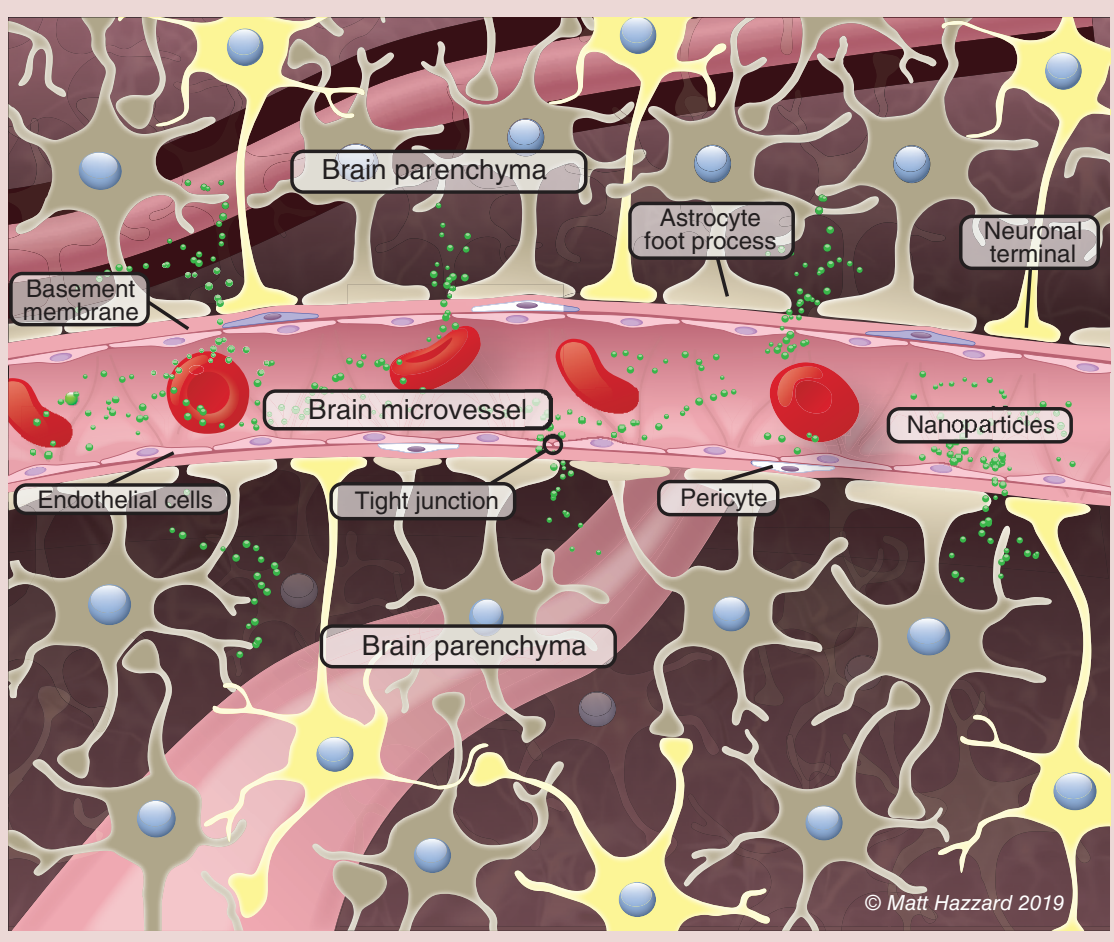

Figure 1. Brain vasculature and components of the blood-brain barrier/neurovascular unit in relation to brain parenchyma.

of tight junctions between adjacent BMEC surfaces. Intact tight junctions prevent passage of ionic substances as small as lanthanum (hydrated ionic diameter $\sim 0.8 \mathrm{~nm}$ ) through this paracellular barrier [1]. Microvessels, the blood vessels between arteries and veins, are approximately $7.5 \mu \mathrm{m}$ in diameter [2], barely large enough for a red blood cell to squeeze through. Microvessels deliver blood to the brain from within the brain [3].

There are 100 billion capillaries, approximately $600 \mathrm{~km}$ long, with a surface area of $20 \mathrm{~m}^{2}$ within the human brain. These microvessels provide a blood supply within approximately $10 \mu \mathrm{m}$ of every brain cell [4], as illustrated in Figure 1 by the foreground and two background microvessels. They occupy approximately 2\% of cortical brain volume and a greater space in some other brain regions [5,6]. Pericytes extend over approximately $30 \%$ of the BMEC surface. Surrounding the BMECs and pericytes is a basement membrane, covering the abluminal (brain-side) BMEC surface (Figure 1). Foot processes of astrocytes, one of the brain's glial cells, cover more than $90 \%$ of the abluminal basement membrane surface (Figure 1). Neurons interact with this cell complex to form the neurovascular unit (Figure 1). For an NP to enter brain parenchyma from blood, it must either distribute through a BMEC (transcellular) or between BMECs (paracellular), as suggested in Figure 1. The latter is not expected when the BBB is intact but can occur when the BBB is opened (leaky, e.g., there is increased space between adjoining BMEC surfaces). This occurs in cancer (at the blood-tumor barrier), Alzheimer's disease, traumatic brain injury, multiple sclerosis, infections, encephalitis, stroke, liver failure and other less common conditions $[7,8]$. BBB opening can be produced by osmotic insult, for example, $25 \%$ mannitol infusion into a carotid artery that delivers blood directly to its ipsilateral hemisphere [9] or focused ultrasound in conjunction with systemically circulating microbubbles [10].

\section{Potential pitfalls of experimental result misinterpretation}

Given the intimate spatial relationship between the microvessels of the vascular compartment and brain parenchyma, visual demonstration of brain parenchymal entry in vivo or in situ requires $\leq 10 \mu \mathrm{m}$ resolution. Alternatively, one could use methods that separate BBB components from brain parenchymal components. Failure to distinguish brain parenchymal NP entry from bulk brain can result in the interpretation that an NP has crossed the BBB when it may not have or did not to the extent implied. For example, IVIS demonstration of increased fluorescence in the head region from an NP component does not differentiate whether the NP is in the skull; the blood in 
the vessels surrounding and within the brain; associated with the luminal side of BMECs; within or between the BMECs; between the BMECs and basement membrane; within the basement membrane, pericytes or astrocyte foot processes; or in brain parenchyma.

There have been many studies addressing brain entry of many different NPs that concluded they entered the brain, without demonstration that they crossed the BBB and entered brain parenchyma. Considering the brain as the cranial contents, the claim of NP brain entry can be accepted if it is shown that the NP is in bulk brain. But this does not demonstrate brain parenchymal entry. For most studies, the methods employed were not able to differentiate NPs in the blood versus associated with BBB components versus residing in brain parenchyma, as differentiated in Figure 1.

\section{NPs in or associated with the vascular compartment contribute to bulk brain but not brain parenchymal content}

Rats perfused to remove blood (from the vascular compartment) $4 \mathrm{~h}$ after intravenous injection of gold glyconanoparticles had only approximately $4 \%$ as much NP component in bulk brain as rats that had not been perfused [11]. Similar perfusion reduced gold in three bulk brain regions to $7-18 \%$ of that seen in nonperfused rats [12]. This demonstrates that a great percentage of NPs in bulk brain may not be in brain parenchyma. Removal of blood from the entire body can be accomplished in the deeply anesthetized rodent by transcardial perfusion; introducing a perfusate into the left ventricle and ligating the right auricle to allow blood and perfusate drainage. Perfusate can be $0.9 \%$ sodium chloride or $0.1 \mathrm{mM}$ phosphate @ $\mathrm{pH} 7.4$. For electron microscopy, 4\% paraformaldehyde and 3.5\% glutaraldehyde in cacodylate/phosphate-buffered saline/saline buffer should be used. Gage et al. provide a protocol [13]. Some studies accounted for the contribution of blood NPs within the brain to their bulk brain level [6,14-18]. NPs in bulk brain blood were estimated from the product of the peripheral blood NP concentration $\times$ brain vascular volume. However, this does not account for NPs adsorbed to the BMEC luminal wall or in BBB cellular and membrane components. After intravenous injection to rodents, NPs were observed adhered to the luminal wall of blood vessels in the brain with little to no evidence of brain tissue entry. This was seen for lipid (stearic acid and polysorbate 80) drug conjugate NPs [19], 100-nm wide and 300-nm long poly(ethylene glycol) (PEG)-polyethylenimine-conjugated mesoporous silica NPs [20], and a 5-nm polyhedral citrate-coated ceria NP that had a surface charge of $-53 \mathrm{mV}$ [21]. In Dan et al's study, blood was removed from the brain by ceria-free perfusion. The preponderance of NPs in guinea pig brain that had been infused for $120 \mathrm{~min}$ with approximately 8-nm amphipathic hydrophilic/hydrophobic-coated gold/iron core NPs followed by $30 \mathrm{~min}$ perfusate washout was in endothelial cells [22]. These observations are in agreement with a kinetic study that reported a negatively charged NP associated with cell surfaces within seconds, by Langmuir adsorption through electrostatic interaction [23]. These results demonstrate the potential contribution of BBB-associated NPs to bulk brain content, even after removal of blood from the brain.

The importance of distinguishing among NP distribution in the vascular compartment, the cells comprising the BBB and brain parenchyma is nicely illustrated by the results of Fiandra et al. [24]. Employing fluorometric dye fluorescein isothiocyanate (FITC)-labeled amphiphilic polymer-coated iron oxide NPs containing a fluorometric dye (AF660)-labeled antiretroviral drug, they differentiated localization of the drug from the nanoconstruct. Confocal laser scanning microscopy (CLSM) viewing of mouse brain sections stained to identify the BMECs demonstrated colocalization of the NPs and BMECs, interpreted as NP residence in the vascular compartment. Antiretroviral drug was seen within and outside of the vascular compartment, interpreted as having been released from the NPs. Similarly, using a GFAP antibody to identify blood vessels by the astrocyte foot processes that cover them, Dal Magro et al. saw considerable NPs surrounded by the GFAP antibody, but some particles that were not, the latter interpreted as having entered brain parenchyma [25].

\section{BCSFB anatomy \& function}

The CSF compartment is comprised of four ventricles within the brain (two lateral, a third and a fourth) and the CSF-filled subarachnoid space that surrounds the entire CNS. CSF is produced by choroid plexuses in each of the four ventricles and diffusion of extracellular fluid from the brain. Each lateral ventricle has a single outlet, to the third ventricle, that drains into the fourth ventricle, that drains into the subarachnoid space, creating one-directional flow out of the brain. CSF in the human and rat turns over approximately four- and ten-times daily, respectively. It exits from this compartment through arachnoid granulations into dural sinuses then into blood (via the jugular veins). The epithelial cells of the choroid plexuses have tight junctions, efflux transporters and metabolic properties 
Table 1. Studies that reported the brain level of the nanoparticle or component(s) at multiple times after convection enhanced delivery. Mean residence time values were determined as described in nanoparticle kinetics in the brain.

\begin{tabular}{|c|c|c|}
\hline Study summary & MRT (h) & Ref. \\
\hline The percent of radioactivity in the brain following CED of $82 \mathrm{~nm}{ }^{3} \mathrm{H}$-cholesteryl hexadecyl ether liposomes was determined & 22 & [83] \\
\hline $\begin{array}{l}\text { The rat brain hemisphere that received CED of } 0.06,0.8 \text { or } 1.6 \mathrm{mg} \text { of } 96-101 \mathrm{~nm} \text { irinotecan-loaded nanoliposomes was perfused and } \\
\text { homogenized, centrifuged, and irinotecan analyzed by the HPLC. Half-life of the three doses was } 6.7,10.7 \text { and } 19.7 \text { days, respectively }\end{array}$ & 108,181 and 400 & [81] \\
\hline $\begin{array}{l}\text { Brains from rats that received CED of } 105-122 \mathrm{~nm} \text { topotecan-loaded liposomes was perfused, the infused hemisphere removed, } \\
\text { homogenized, centrifuged and topotecan analyzed by the HPLC. Half-life was } 1.5 \text { days }\end{array}$ & 44 & [84] \\
\hline $\begin{array}{l}\text { The rat brain hemisphere that received CED of a mixture of } 95-110 \mathrm{~nm} \text { doxorubicin-loaded pegylated liposomes or irinotecan-loaded } \\
\text { nanoliposomes was perfused, homogenized, centrifuged and irinotecan and doxorubicin analyzed by the HPLC. Half-life was } 10.9 \text { and } \\
16.7 \text { days, respectively }\end{array}$ & 273 and305 & [79] \\
\hline $\begin{array}{l}\text { Local retention of radioactivity after intratumor CED of } 135 \mathrm{~nm}{ }^{186} \text { Re-loaded liposomes was determined in rat brain by gamma } \\
\text { camera. Half-clearance time was } 54.6 \mathrm{~h}\end{array}$ & 50 & [85] \\
\hline $\begin{array}{l}\text { Brain MRI was obtained after CED of human serum albumin-, PEG- and methotrexate/human serum albumin-coated } 20 \mathrm{~nm} \gamma-\mathrm{Fe}_{2} \mathrm{O}_{3} \\
\text { NPs }\end{array}$ & 190, 184and 198 & [80] \\
\hline IVIS imaging was conducted after CED of EGFR-coated quantum dot-containing immunoliposome hybrid NPs to mice with brain tumors & 97 & [86] \\
\hline $\begin{array}{l}\text { Positron emission tomography imaging was conducted after CED of } 71 \text { and } 147 \mathrm{~nm}\left[{ }^{18} \mathrm{~F}\right] \text {-fluorobenzylamine, NHS-PEG- biotinylated, } \\
\text { avidin-modified PLGA NPs to rats. Half-life was } 111 \mathrm{~min}\end{array}$ & 0.39 & [87] \\
\hline $\begin{array}{l}\text { Rat brain containing the region of CED of } 175 \mathrm{~nm} \text { carboplatin-labeled fluorescein-PLGA NPs was homogenized and platinum } \\
\text { determined by ICP-MS }\end{array}$ & 18 & [88] \\
\hline $\begin{array}{l}\text { The hemisphere that received CED of } 60-100 \mathrm{~nm} \text { radiosensitizer (VE822)-loaded PEG-conjugated, } \\
\text { poly( } u \text {-pentadecalactone-co-p-dioxanone) NPs, of varying PEG polymer ratios, was analyzed by LC-MS for VE822. Half-life was } 12 \mathrm{~h}, 2 \\
\text { and } 5 \text { days }\end{array}$ & 46,61 and 68 & [89] \\
\hline $\begin{array}{l}\text { Fluorescence images of mice brain sections were obtained after intrastriatal CED of Cy5.5 fluorophore-labeled peptide-based } \\
\text { nanofibers (5-nm width, 100, } 400 \text { and } 1000 \mathrm{~nm} \text { length) }\end{array}$ & 20,25 and 29 & [29] \\
\hline $\begin{array}{l}\text { MRI imaging was conducted for } 48 \mathrm{~h} \text { after CED of } 54-\mathrm{nm} \text { iron oxide chitosan-PEG NPs modified with a glioma-targeting ligand to } \\
\text { mice-bearing brain tumors. Signals near the point source of the infusion of NP without and with ligand were used to calculate the MRT }\end{array}$ & 3.4 and 4.8 & [90] \\
\hline \multicolumn{3}{|c|}{$\begin{array}{l}\text { CED: Convection-enhanced delivery; HPLC: High-performance liquid chromatography; ICP-MS: Inductively coupled plasma mass spectrometry; IVIS: In vivo imaging system; LC- } \\
\text { MS: Liquid chromatography-mass spectrometry; MRT: Mean residence time to the last sample; NHS: N-hydroxysuccinimide; NP: Nanoparticle; PEG: Polyethylene glycol; PLGA: } \\
\text { Poly(D,L-lactide-co-glycolide). }\end{array}$} \\
\hline
\end{tabular}

similar to the BBB, creating the BCSFB between blood and CSF. There is little barrier to distribution between CSF and the brain, so substances injected into the CSF compartment, or able to cross the BCSFB, readily diffuse into the brain proximal to the CSF compartment.

Material entry into the nervous system, including the brain, might also be achieved by its introduction into the CSF compartment. In the human, this is most often accomplished by injection into CSF in the spinal region. Given CSF flow, NP injection into CSF would not be expected to persist for a long time compared with introduction into brain parenchymal space. As distribution from CSF into the CNS (brain and spinal cord) is by diffusion, and against extracellular fluid flow toward CSF, significant distribution very far into the brain would not be expected. Demonstration of successful NP distribution into brain parenchyma via this route would require similar techniques as apply to NP introduction into blood.

\section{Convection-enhanced delivery of solutions into the extracellular brain space}

A method to directly deliver solutions into the brain is convection-enhanced delivery (CED). In CED, the tip of a catheter is stereotaxically inserted into the brain through a hole in the cranium. A solute (drug or NP)-containing solution is infused through the catheter by a pump. Solute release from the catheter tip into brain extracellular space displaces extracellular fluid. The solute distributes through brain extracellular space surrounding the catheter tip by bulk flow to create a radial distribution up to a few centimeters. After termination of the infusion, the solute may continue to redistribute by bulk flow and diffusion as it is being locally cleared. CED has advantages of bypassing the BBB enabling brain parenchymal delivery of drugs that do not cross the BBB, delivery to a target site that can be deep within the brain and creation of much higher regional than distal brain and systemic drug concentration. It is most commonly used to treat glioblastoma multiforme, a brain cancer that has a poor prognosis [26-28]. Small molecules are cleared within $72 \mathrm{~h}$ [29], whereas some NPs have been found to persist for much longer (Table $1 \&$ Supplementary Figure 1). 
Table 2. Visual methods that might be used to image brain nanoparticle distribution and their reported resolution.

\begin{tabular}{|c|c|c|}
\hline Method & Resolution & Ref. \\
\hline High-resolution brain MRI & $\geq 120 \mu \mathrm{m}$ & [91] \\
\hline Photoacoustic microscopy & $20-100 \mu \mathrm{m}$ & [37] \\
\hline IVIS spectrum & $20 \mu \mathrm{m}$ & [92] \\
\hline MSI & Submicron for some methods & [93] \\
\hline Super resolution (light) microscopy (aka: single-molecule localization microscopy) & $<100 \mathrm{~nm}$ & {$[38,94-96]$} \\
\hline Hyperspectral imaging & $<10 \mathrm{~nm}$ & {$[44,97,98]$} \\
\hline CLSM & $2 \mu \mathrm{m}$ & [99] \\
\hline Electron microscopy & $<1 \mathrm{~nm}$ & [100] \\
\hline CLEM & $>50 \mathrm{~nm}$ for $\mathrm{LM},<1 \mathrm{~nm}$ for EM & {$[59,61]$} \\
\hline
\end{tabular}

CLEM: Correlative light and electron microscopy; CLSM: Confocal laser scanning microscopy; EM: Electron microscopy; IVIS: In vivo imaging system; LM: Light microscopy; MSI: Mass spectrometry imaging.

\section{Nasal cavity route of delivery directly to the CNS}

There is only one site where the nervous system is directly exposed to the external environment of mammals, where direct uptake of NPs into the nervous system might occur. This is the roof of the nasal cavity where the olfactory neuron and the maxillary branch of the trigeminal neuron have terminals with receptors that mediate the perception of sensory stimuli, including smell. This route of administration, introducing test material into the nose (intranasal), is being investigated for NP entry into the brain, to bypass the BBB. Demonstration of NPs in these sensory neurons ex vivo (e.g., by electron microscopy visualization or elemental analysis under conditions that rule out dissolution or degradation that releases NP components), or of NPs within the nerve when it is in situ, provides confidence of nerve entry. The olfactory and trigeminal neurons are surrounded by CSF, so suggestion of NP in the region of the nerve, for example, from an NP fluorescent molecule, does not unequivocally show nerve entry. Although neuropeptides have been shown to enter CSF directly from the nasal cavity, this route was shown to not contribute to uptake of $110 \mathrm{~nm}$ 6-coumarin-loaded (for visualization) PEG-poly(lactic acid) NPs [30]. There have been demonstrations of NP uptake by the olfactory or trigeminal nerve. NPs often accumulate in the olfactory bulb, with little or no distribution across the synapse between the olfactory bulb and the next neuron of the olfactory system that would enable distribution to distal brain regions (e.g., the pyriform cortex, amygdala, thalamic and hypothalamic nuclei, and hippocampus) after intranasal administration. Olfactory bulb accumulation was shown with colloidal gold [31,32], ${ }^{13} \mathrm{C}$ carbon [33], nanoscale manganese oxide [34] and quantum dots [35]. Distribution of quantum dots from the nasal cavity to the olfactory bulb was attributed to microtubule-mediated fast axonal transport (200-400 mm/day), because axonal flow is too slow to account for the timecourse of its appearance in the olfactory bulb [35]. Based on the olfactory nerve length from the nasal cavity to the olfactory bulb ( $\sim 5$ and $8 \mathrm{~mm}$ in mice and rats, respectively) fast axonal transport could traverse this with an NP in approximately 26-40 min. Much more time would be required for neuronal NP transport from the nasal cavity to distant brain regions, such as the striatum. Rapid appearance of NPs or NP components in distant sites can be attributed to absorption from the nasal cavity into systemic circulation followed by distribution into the brain. Translocation of NPs from the nasal cavity to the brain is low. Gamma counting of whole brain $24 \mathrm{~h}$ after intranasal ${ }^{111}$ In-labeled protein NP suggested approximately $0.2 \%$ of the dose was in the brain, assuming stability of the ${ }^{111}$ In-NP complex [36]. No studies were found demonstrating NP entry into brain parenchyma beyond the olfactory bulbs after intranasal administration.

\section{Methods to demonstrate NP brain parenchymal entry}

To definitively claim that an NP has entered brain parenchyma requires methods that differentiate NP distribution in brain parenchyma from blood within the brain and BBB components. One approach is to use visual methods.

\section{Visual methods to demonstrate NP brain parenchymal entry}

Table 2 lists some visual methods and their optimal resolution. High-resolution brain MRI does not provide, even under optimal conditions, sufficient resolution to differentiate NP localization between parenchymal versus nonparenchymal sites. It would not be able to characterize NP morphology, size or chemical identity.

Photoacoustic imaging (tomography) is a hybrid imaging modality that integrates optical contrast with highultrasonic spatial resolution in deep tissue. It can provide noninvasive images of the entire brain with less than msec 
temporal resolution [37], based on the light absorption properties of the tissue and material (e.g., NPs) within it. Although useful for NP-assisted imaging, for example, of brain tumors, it lacks sufficient resolution to differentiate NP localization between parenchymal versus nonparenchymal sites.

The IVIS spectrum in vivo imaging system combines $2 \mathrm{D}$ and $3 \mathrm{D}$ optical tomography into a single platform to visualize fluorescence and bioluminescence. It has been extensively used to demonstrate the intensity of fluorescent NPs in organs in vivo and ex vivo. Intensity in the head region has been claimed by many as evidence of the NP in the brain. It is noninvasive and can be used with living organisms. However, even if used to localize NPs in ex vivo tissue, it does not have sufficient resolution to differentiate NP localization between parenchymal versus nonparenchymal sites.

Mass spectrometry imaging (MSI) includes many techniques, such as laser desorption/ionization mass spectrometry, matrix-assisted laser desorption ionization, (time-of-flight) secondary ion mass (SIM) spectrometry and desorption electrospray ionization. It has been used with surface-functionalized gold- or gadolinium-containing NPs to localize organics such as lipids, metabolites and proteins in the brain. Although some forms of MSI have submicron resolution (e.g., SIM), no reports were found using MSI to verify brain parenchymal NP localization.

Super-resolution microscopy utilizes fluorescent microscopes in a variety of approaches, categorized as those that approach the diffraction limit $(0.25 \mu \mathrm{m}$ in the focal plane) and those that break the diffraction limit by turning fluorescent markers on and off. In the latter rather than all fluorescent molecules emitting simultaneously (as occurs in conventional fluorescence microscopy), a small subpopulation is excited so that emission from neighbors does not overlap, enabling isolation of individual emitters [38]. Approaches include stochastic optical reconstruction microscopy, direct stochastic optical reconstruction microscopy, photoactivated localization microscopy, fluorescence photoactivated localization microscopy and ground-state depletion with individual molecule return. Super-resolution microscopy has been used to image the NP protein corona [39,40] and localize NPs in cells [41,42], but no reports were found of in vivo, in situ or ex vivo NP localization.

Hyperspectral imaging combines imaging and spectrophotometry by capturing spectral data of infrared and visible light reflected by samples at each pixel in an enhanced dark-field microscopic image. For this to differentiate vascular versus parenchymal NP localization, an enhanced dark-field microscopic image needs to be interpreted first to identify the region of interest, then hyperspectral imaging employed to provide spectrophotometric data. This was demonstrated in studies that showed cellular sites of functionalized gold NPs [43]; studies that included cellular, C. elegans, and Japanese medaka NP distribution cited by Roth [44]; and porcine skin uptake of metal oxide NPs [45]. This approach might enable differentiation of NP localization between brain parenchymal versus vascular sites, but no such studies were found.

Fluorescence microscopy visualizes fluorescent tags or incorporated molecules (e.g., doxorubicin and paclitaxel). With the exception of transmission electron microscopy (TEM), the only studies using a method in Table 2 that appear to have differentiated NP parenchymal from vascular space distribution used fluorescence microscopy and CLSM. Using fluorescence microscopy, Mulik et al. saw fluorescent-labeled NPs within brain cells [46]. Åslund et al. used CLSM to image fluorescent dye-containing NPs, and tomato lectin-labeled blood vessels, and saw NP fluorescent dye outside of the brain microvasculature [47]. Some details of these studies and those reported by others who used CLSM are below and/or in Table 4 [22,24,25,47-55].

Electron microscopy, typically TEM, is not only the best technique to characterize prepared NPs, it is also amenable to physicochemically identify and characterize NPs in samples obtained from biological environments [5658]. It provides the greatest resolution among the options in Table 2 , and when equipped with capabilities such as high-angle annular dark-field detection, energy dispersive x-ray spectroscopy or electron energy loss spectroscopy, it enables chemical characterization.

The benefits of light microscopy (including identification of biological structures and location of regions of interest and fluorescent labels) have been combined with the benefits of electron microscopy (to provide NP localization and physicochemical information) in correlative light and electron microscopy (CLEM) [59]. The two approaches were independently used to locate NPs in a murine brain tumor model [60]. CLEM has been developed in a single instrument and used to localize NPs in cultured non-neuronal cells [61]. No studies were found utilizing CLEM to investigate NP brain parenchymal entry.

Several of the above methods are based on detection of a label added to the NP, often a fluorescent molecule or $\mathrm{metal} / \mathrm{metal}$ oxide. Correct interpretation of NP localization, when based on an added label, requires NP preparation that does not contain free label (which can be removed by dialysis) and understanding the label stability in vivo. Fluorescent molecules are susceptible to loss of their signal due to quenching (due to interaction with local molecular 
environmental components) and photobleaching (excitation light-induced destruction of the excited fluorophore). Persistent association (stability) of the label and the NP in vivo is required to attribute label signal to NP localization. Label dissociated from the NP will yield a different distribution than the label-NP complex. Covalent binding of label to an NP decreased label release, compared with encapsulation of the label [62]. Incorporation of the label in the NP core did not produce changes in the NP surface properties [63]. Label dissociation from a biodegradable polymer NP would be expected over time. Label dissociation can be assessed in vitro by incubation of the labeled NP with brain homogenate [30] or separation of the NP and brain components from the released label, for example, by NP centrifugation, and detection of label in the supernatant. Other considerations include the potential for the label to alter the physicochemical properties of the NP and its resultant distribution and biological tolerance to the label. More in-depth discussions can be found in $[64,65]$.

\section{Methods to demonstrate NP brain parenchymal entry}

Methods are available to assess whether NPs introduced into the vasculature perfusing the brain are associated with BBB components and/or crossed the BBB to enter brain parenchyma. The in situ brain perfusion technique can be used to determine NP entry rate and extent of distribution into bulk brain, multiple bulk brain regions and/or the choroid plexus, ipsilateral to the carotid artery perfused after short-term (few minutes or less) intracarotid infusion [66]. An intracarotid perfusion rate sufficiently high to prevent blood from entering the perfused carotid artery is used, therefore preventing blood from entering the brain hemisphere perfused by that artery. This enables control of the chemical environment of the material tested (therefore its chemical form [speciation]), based on the perfusion fluid composition and avoidance of blood exposure. Preventing blood exposure avoids potential NP biotransformation (e.g., corona coating by plasma proteins, dissolution or particle breakdown) that might change its surface properties and brain uptake. Although the in situ brain perfusion technique removes blood from the brain vasculature, it does not distinguish NP distribution associated with the BBB versus brain parenchyma, nor choroid plexuses from brain unless they are separated.

The capillary depletion method is intended to separate BBB components from brain parenchyma, to produce capillary-depleted brain parenchyma [67]. This is often conducted with brain tissue obtained using the in situ brain perfusion technique but can be used with brain tissue obtained by other methods that remove blood from the brain. The methods are described in detail in [68]. The capillary depletion method uses centrifugation of brain homogenate in dextran that separates the BMECs into the pellet (along with brain nuclei and erythrocytes if blood was not perfused from the brain) from the supernatant that contains brain cells and brain extracellular fluid. Presence of the test material in the supernatant is taken as evidence that it has transcytosed the BBB into brain parenchyma. This method was employed to ascertain the fraction of 190-nm poly(n-butyl cyanoacrylate) (PBCA)-coated doxorubicin-loaded NPs that entered brain parenchyma [69]. Doxorubicin was seen in the brain fraction after intravenous administration in NPs but not when doxorubicin solution was administered with $1 \%$ polysorbate 80 (intended to open the BBB). Coating the NPs with $1 \%$ polysorbate 80 increased the doxorubicin supernatant to pellet ratio, suggesting the surfactant-coated PBCA NPs entered brain parenchyma. Employing the capillary depletion method after whole body perfusion to remove blood, it was shown that the percentage of the injected dose of ${ }^{111}$ In-DTPA-multiwalled carbon nanotubes (median diameter: 18.9 and length: $500 \mathrm{~nm}$ )

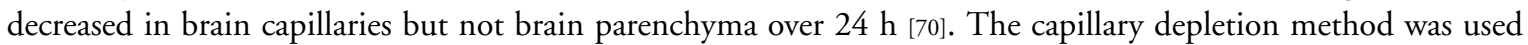
to obtain curcumin for LC-MS/MS analysis from mouse brains after oral dosing of a curcumin-containing NP. The report does not state if the brain was perfused prior to harvest. If not the supernatant fraction would be expected to include blood plasma contents that could have contained some/all of the curcumin [71]. The capillary depletion method was used to demonstrate that cationic bovine serum albumin-coated biodegradable polymersomes ( $\sim 100 \mathrm{~nm}$, composed of PEG- and maleimide-PEG-poly( $\varepsilon$-caprolactone), loaded with coumarin-6) entered brain parenchyma. The supernatant fraction increased from a half to $1 \mathrm{~h}$ and was fairly stable for $4 \mathrm{~h}$, and increased over the $4 \mathrm{~h}$ in relation to the pellet (vascular fraction) [72]. Capillary depletion was used in transcardially perfused mice to assess the influence of transferrin-receptor antibody density on gold NPs and platinum-containing liposomes to enter brain parenchyma [73]. $2.5 \mathrm{~h}$ after intravenous injection, gold and platinum in the parenchymal fraction were approximately 27 and $22 \%$ of the combined parenchymal and capillary fractions, respectively. In contrast to demonstrating brain parenchymal entry, the capillary depletion method suggested nearly all of 5-nm ceria in the brain was associated with the capillary endothelial cells, consistent with EM observations of nanoceria adhered to the luminal side of blood vessel walls in the brain, noted above [21]. 


\begin{tabular}{|c|c|c|}
\hline Level & Description of results & Interpretation \\
\hline 1 & $\begin{array}{l}\text { NP component (e.g., fluorescent dye, element) in bulk brain or ex vivo brain not perfused of } \\
\text { blood. Determined by methods such as IVIS, radioactivity, NAA, ICP-MS, AAS or HPLC }\end{array}$ & A NP component was in bulk brain \\
\hline 2 & $\begin{array}{l}\text { NP component (e.g., fluorescent dye, element) in bulk brain or ex vivo brain perfused to } \\
\text { remove blood. Determined by methods such as IVIS, radioactivity, NAA, ICP-MS, AAS or HPLC }\end{array}$ & $\begin{array}{l}\text { A NP component was in bulk brain, but not in the } \\
\text { blood within the brain }\end{array}$ \\
\hline 3 & $\begin{array}{l}\text { Intact NP in bulk brain not perfused of blood. Determined by methods such as bulk } \\
\text { brainhomogenization, NP isolation and verification (e.g., visual, perhaps also requiring } \\
\text { chemical) }\end{array}$ & The NP was in bulk brain \\
\hline 4 & $\begin{array}{l}\text { Intact NP in bulk brain perfused to remove blood. Determined by methods such as bulk brain } \\
\text { homogenization after perfusion to remove blood, NP isolation and verification (e.g., visual, } \\
\text { perhaps also requiring chemical) }\end{array}$ & $\begin{array}{l}\text { The NP was in bulk brain, but not in the blood } \\
\text { within the brain }\end{array}$ \\
\hline 5 & $\begin{array}{l}\text { NP component isolated from brain parenchyma. For example, using the capillary depletion } \\
\text { method of brain perfused to remove blood to obtain brain parenchyma and a method to } \\
\text { identify the NP component, for example, radioactivity, ICP-MS, AAS or HPLC. For example, } \\
\text { microdialysis to recover an NP component from brain extracellular fluid, in the presence of an } \\
\text { intact BBB }\end{array}$ & A NP component was in brain parenchyma \\
\hline 5 & $\begin{array}{l}\text { NP component (e.g., fluorescent dye, element) visualized in brain areas or cells not associated } \\
\text { with brain vasculature. Determined by methods such as MSI, single-molecule localization } \\
\text { microscopy, hyperspectral imaging or CLSM }\end{array}$ & A NP component was in brain parenchyma \\
\hline 6 & $\begin{array}{l}\text { Intact NP isolated from brain parenchyma. For example, using the capillary depletion method } \\
\text { of brain perfused to remove blood to obtain brain parenchyma and a method to verify intact } \\
\text { NPs (e.g., visual, perhaps also requiring chemical) }\end{array}$ & The NP was in brain parenchyma \\
\hline 6 & $\begin{array}{l}\text { Intact NP visualized in brain areas or cells not associated with brain vasculature. } \\
\text { Determined by methods such as TEM, with chemical verification, such as EDS or EELS }\end{array}$ & The NP was in brain parenchyma \\
\hline \multicolumn{3}{|c|}{$\begin{array}{l}\text { The level of demonstration of nanoparticle brain or brain parenchymal entry is in the first column. } \\
\text { AAS: Atomic absorption spectroscopy; BBB: Blood-brain barrier; CLSM: Confocal laser scanning microscopy; EDS: Energy dispersive x-ray spectroscopy; EELS: Electron energy loss } \\
\text { spectroscopy; HPLC: High-performance liquid chromatography; ICP-MS: Inductively coupled plasma-mass spectrometry; IVIS: In vivo imaging system; MSI: Mass spectrometry } \\
\text { imaging; NAA: Neutron activation analysis; NP: Nanoparticle; TEM: Transmission electron microscopy. }\end{array}$} \\
\hline
\end{tabular}

NP components have been sampled from the brain using microdialysis probes [74-77]. In the presence of an intact $\mathrm{BBB}$, it is assumed that this technique samples brain extracellular space. Microdialysis probes with 30 and $100 \mathrm{kDa}$ molecular weight cutoff membranes would be expected to allow penetration of up to 5-8 and 8-14 nm (depending on membrane composition) diameter spherical particles and molecules released from NPs. The appearance of an NP component in the dialysate from a probe would not conclusively demonstrate NP distribution into brain parenchyma. None of the above studies demonstrated that intact NPs were recovered in the dialysate.

\section{Level of demonstration of NP brain or brain parenchymal entry \& critical review of study claims}

Convincing demonstration of brain parenchymal entry is limited to in vivo studies. In vitro BBB models do not recapitulate $\mathrm{BBB}$ complexity. They lack all of its cell composition, cell interactions, cell spatial relationships and magnitude of resistance to distribution across them. Therefore, this report is limited to in vivo, in situ and ex vivo brain studies. Many reports published within the past 5 years were identified by a SciFinder search of the terms NP and brain, a SciFinder search of the terms NP and BBB for reports published in 2019, and a PubMed search of NPs, drug delivery systems and brain parenchyma. The reports were reviewed, summarized and critiqued for evidence supporting claims in the report and classified for the level of demonstration of NP brain or brain parenchymal entry, as defined in Table 3. Some reports published more than 5 years ago that are informative for their demonstration of NP brain parenchymal entry and/or reported brain NP concentration at multiple times are included. The results are in Table 4.

\section{NP kinetics in the brain}

Endocytosis is the prevalent mechanism that mediates NP transport across the intact BBB. It would not be anticipated that after NPs cross the BBB and enter brain parenchyma they would be rapidly cleared from that compartment [78]. After NP infusion directly into the brain by CED, HPLC determination of two components showed clearance half-lives of 250-400 h (Table 1) [79]. MRI-determined NP distribution volume after CED decreased $50 \%$ in approximately $250 \mathrm{~h}$ (Table 1) [80]. Some details of these and other studies that reported brain $\mathrm{NP}$ or component levels at multiple times after CED are in Table 1. Brain clearance half-life was shown to be dose 
Table 4. Brain nanoparticle distribution study claims, summary, critique, support for the claims and level of brain or brain parenchymal entry.

\begin{tabular}{ll} 
Claim & Study summary \\
\hline 'Uptake of NPs in the brain' & $\begin{array}{l}\text { Whole organs were solubilized for radioactivity } \\
\text { determination after iv. injection of } 131-\mathrm{nm} \\
\text { surfactant-coated poly }\left({ }^{14} \mathrm{C}-\text { methyl methacrylate) particles }\right.\end{array}$ \\
\hline
\end{tabular}

‘Doxorubicin was in brain tissue'

Whole organs were homogenized, proteins precipitatedand doxorubicin determined by HPLC after iv. injection of 90-nm doxorubicin-loaded solid lipid particles
'Polysorbate 80-coated polybutylcyanoacrylate NPs could be used to overcome blood-brain barrier'

'ICP-MS results indicated that 17 and $37 \mathrm{~nm}$ [gold NPs] were blood-brain barrier and entering the mouse brain.'

'Brain delivery' capable of passing through the

Visible blood vessels were removed from the cerebrum and cerebellum, whole organs were homogenized, proteins precipitated and methotrexate determined by HPLC after iv. injection of 70-345 nm methotrexate-loaded PBCA NPs

aWhole brain was homogenized, separated by HPLC, and gold quantified by ICP-MS after ip. injection of 17- and 37-nm gold particles.

bTEM and EDS showed electron-dense particles in the cytoplasm of hippocampal pyramidal cells and gold

Whole brain from transcardially perfused rats was homogenized for gold quantitation by NAA after ip. injection of peptide-conjugated,citrate-coated 12-nm gold particles. Whole brain from transcardially perfused rats was prepared for fluorescence microscopy after ip. injection of carboxyfluorescein-labeled, peptide-conjugated, citrate-coated 12-nm gold particles

'Focused ultrasound and magnetic targeting synergistically deliver therapeutic MNPs across the blood-brain barrier to enter the brain'

a Whole brain was prepared for ICP-OES iron and HPLC epirubicin determination after iv. injection of 12-nm magnetic NPs into rats whose BBB had been opened by iv. injection of microbubbles and focused ultrasound.

${ }^{b}$ TEM of similarly treated rats with brain tumors showed electron densities inside tumor cells and macrophages

'NP deposits were widely distributed throughout brain, with apparent cellular uptake
Critique, support for claim and

level of demonstrated NP brain entry

distribution to the brain, which is

not shown. Bulk brain ${ }^{14} \mathrm{C}$

\section{Claim assumes intact NP} presence shown; 1

MRT (h)

$42(47)$

HPLC results of NP component

$1.8(1.8)$

102

show bulk brain uptake; 1

HPLC analysis of NP component

1.8 and 1.9

in bulk brain does not

demonstrate distribution across

the BBB; 1

a ICP-MS results of NP component Increased from

bulk brain do not demonstrate 336to 504

distribution through the BBB; 1 . h after injection

${ }^{b} T E M / E D S$ results demonstrate

distribution across the BBB; 6

NAA results of NP component in No consistent brain homogenate and increase or

concurrent fluorescence show decrease over bulk brain uptake; 2

$24 \mathrm{~h}$

a ICP-OES and HPLC demonstrate 1 bulk brain but not parenchymal

11

entry; 1.

${ }^{\mathrm{b}}$ TEM demonstrates delivery

across the $\mathrm{BBB}$ in the presence of

BBB opening, assuming the

electron densities are iron; 6

amage shows increased

${ }^{\mathrm{c}} 4.3$ and 2.1

[36]

intranasal dosing of 299-nm fluorescent- and fluorescence within cells; 5 .

ovalbumin-loaded cationic liposomes revealed the label in ${ }^{b}$ Colocalization shows

the striatum and substantia nigra.

bProtein immunohistochemistry of perfused rat brain

demonstrated protein and tyrosine hydroxylase

co-localization in striatum and substantia nigra.

'Gamma counting of whole brain after intranasal dosing

of $50 \mu \mathrm{g}{ }^{111} \mathrm{In}$-labeled NP in 1 or $2 \mu \mathrm{g} / \mu \mathrm{l}$ suggested

approximately $0.2 \%$ of the dose was in the brain, assuming stability of the ${ }^{111}$ In-NP

'[Curcumin-loaded PLGA NPs] could cross the blood-brain

Brains from perfused rats were dissected into parts, homogenized, proteins precipitated and curcumin determined by HPLC after iv. injection of 163-nm curcumin-loaded PLGA NPs Reported MRT was $27 \mathrm{~min}$

barrier (BBB) to enter brain tissue'

The whole rat and ex vivo brain were bioluminescence

'In vivo brain distribution ... monitored by a real-time fluorescence imaging system' imaged using IVIS and fluorescence microscopic images obtained of brain sections after iv. injection of 190-210 nm fluorescent dye-labeled solid lipid particles

'Brain delivery'

Fluorescence intensity was determined in ex vivo organs from perfused rats after intranasal dosing of odorranalectin-conjugated fluorescent-labeled 90-nm PEG-PLGA NPS cells; 5 Mean residence time from studies that reported brain and blood (in parentheses) levels at multiple times after dosing. Study multiple end points are designated by a, b, c before
the study summary and critique. The level of demonstrated nanoparticle brain entry is from the classification described in Table 3 . The numbers after the sentences in column 3 refer to the level of demonstrated NP brain entry.

AAS: Atomic absorption spectroscopy; BBB: Blood-brain barrier; BBTB: Blood-brain tumor barrier; BMEC: Brain microvascular endothelial cell; BSA: Bovine serum albumin; CLSM: Confocal laser scanning microscopy; EDS: Energy dispersive X-ray spectroscopy; EELS: Electron energy loss spectroscopy; FITC: Fluorescein isothiocyanate; ICP-MS: Inductively coupled plasma-mass spectrometry; ICP-OES: Inductively coupled plasma-optical emission spectroscopy; INAA: Instrumental neutron activation analysis; ip.: Intraperitoneal; iv.: Intravenous; IVIS: In vivo imaging system; MRT: Mean residence time; MSI: Mass spectrometry imaging; NAA: Neutron activation analysis; NP: Nanoparticle; PBCA: Poly(n-butyl cyanoacrylate); RVG: Rabies virus glycoprotein; TEM: Transmission electron microscopy. 
Table 4. Brain nanoparticle distribution study claims, summary, critique, support for the claims and level of brain or brain parenchymal entry. (cont.).

\begin{tabular}{|c|c|c|c|c|}
\hline Claim & Study summary & $\begin{array}{l}\text { Critique, support for claim and } \\
\text { level of demonstrated NP brain } \\
\text { entry }\end{array}$ & MRT (h) & Ref. \\
\hline $\begin{array}{l}\text { 'We observed ... a fourfold } \\
\text { increase of silver content ... } \\
\text { which indicates that AgNPs are } \\
\text { able to cross the blood-brain } \\
\text { barrier (BBB)' } \\
\text { 'AgNPs also gained access to the } \\
\text { brain ... visible as single NPs as } \\
\text { well as clusters' }\end{array}$ & 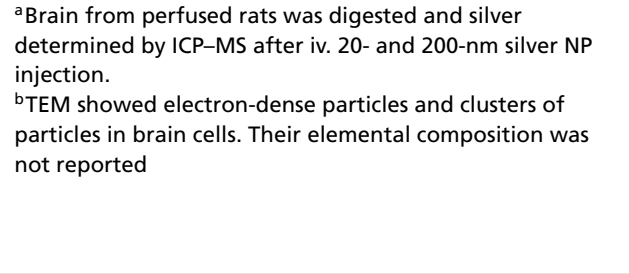 & $\begin{array}{l}\text { a ICP-MS results of NP component } \\
\text { in bulk brain does not } \\
\text { demonstrate distribution across } \\
\text { the BBB; } 1 \text {. } \\
{ }^{\mathrm{b}} \mathrm{NPs} \text { crossed the BBB if the } \\
\text { electron dense particles } \\
\text { contained silver that was not the } \\
\text { result of dissolution then } \\
\text { precipitation; } 6\end{array}$ & $\begin{array}{l}\text { Increased from } \\
24 \text { to } 672 \mathrm{~h} \text { after } \\
\text { injection }\end{array}$ & [110] \\
\hline $\begin{array}{l}\text { 'NPs were localized in the brain } \\
\text { parenchyma' }\end{array}$ & $\begin{array}{l}\text { a Gold in brains from perfused rats was determined by } \\
\text { INAA after ip. injection of transferrin receptor targeting } \\
\text { and } \beta \text {-amyloid destroying peptides conjugated to 37-nm } \\
\text { gold NPs. } \\
\text { bTEM of hippocampus and cortex of perfused rats after ip. } \\
\text { injection of these gold NPs demonstrated intracellular } \\
\text { electron dense spots }\end{array}$ & 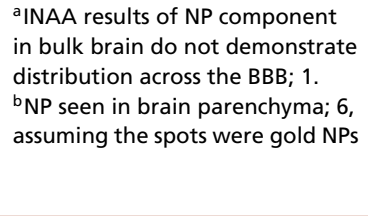 & 8.8 & [111] \\
\hline $\begin{array}{l}\text { 'Suggest that the OX-26-coated } \\
\text { NPs were taken up by the brain' }\end{array}$ & $\begin{array}{l}\text { Microdialysis samples were obtained from the ventral } \\
\text { hippocampus for fluorescence detection of FITC-dextran } \\
\text { after iv. administration of } 140-160 \mathrm{~nm} \text { CD71/OX26-coated } \\
\text { FITC-dextran loaded methoxy-PEG-poly(lactic acid) NPs }\end{array}$ & $\begin{array}{l}\text { NPs were too large to diffuse } \\
\text { through the microdialysis } \\
\text { membrane suggesting } \\
\text { FITC-dextran release; } 5 \text {, assuming } \\
\text { intact BBB }\end{array}$ & 21 & [74] \\
\hline $\begin{array}{l}\text { 'Brain endothelial uptake and } \\
\text { possibly parenchymal } \\
\text { accumulation' }\end{array}$ & $\begin{array}{l}\text { CLSM of fixed brain sections after carotid artery (in situ } \\
\text { brain) perfusion and washout of perfusate or iv. injection } \\
\text { of fluorescent dye-labeled, } \\
\text { polyethylenimine/oligonucleotide-containing liposomes } \\
\text { showed fluorescence associated with BMECs and in the } \\
\text { perivascular space between the BMEC membrane and } \\
\text { parenchymal basement membrane }\end{array}$ & $\begin{array}{l}\text { NP or a component seen beyond } \\
\text { BMECs but not in brain } \\
\text { parenchyma; } 2\end{array}$ & & [51] \\
\hline $\begin{array}{l}\text { 'NPs possess an appreciable BBB } \\
\text { penetrability' }\end{array}$ & $\begin{array}{l}\text { Microdialysis samples were obtained from the right } \\
\text { ventrolateral periaqueductal gray for fluorescence } \\
\text { detection of FITC-neurotoxin after intranasal dosing of } \\
\text { 145-nm chitosan-modified PLA FITC-neurotoxin-containing } \\
\text { NPs }\end{array}$ & $\begin{array}{l}\text { NPs were too large to diffuse } \\
\text { through microdialysis membrane } \\
\text { suggesting FITC- neurotoxin } \\
\text { release; 5, assuming intact BBB }\end{array}$ & 3.3 & [75] \\
\hline $\begin{array}{l}\text { 'Accumulation was achieved in } \\
\text { the brain' }\end{array}$ & $\begin{array}{l}\text { Whole brains from mice were homogenized, proteins } \\
\text { precipitated, and camptothecin determined by HPLC after } \\
\text { iv. injection of } 160 \mathrm{~nm} \text { camptothecin-containing solid lipid } \\
\text { NPs. }\end{array}$ & $\begin{array}{l}\text { HPLC analysis demonstrates bulk } \\
\text { brain accumulation; } 1\end{array}$ & $7.7(7.0)$ & [112] \\
\hline $\begin{array}{l}\text { '[Palmitoyl dalargin] was } \\
\text { detectable } \ldots \text { in the brain' 'pDal } \\
\text { is clearly located in the brain } \\
\text { parenchyma' }\end{array}$ & $\begin{array}{l}\text { aWhole brains were homogenized, proteins precipitated } \\
\text { and palmitoyl dalargin measured by LC-MS in rats after iv. } \\
\text { injection of palmitoyl dalargin fibers. The authors claim } \\
\text { brain parenchymal entry because brain concentration was } \\
\text { greater than can be accounted for by blood, and slower } \\
\text { clearance from brain than blood. } \\
\text { bCoherent anti-Stokes Raman scattering microscopy } \\
\text { revealed pDal fibers within brain parenchyma }\end{array}$ & $\begin{array}{l}\text { a LC-MS of NP component in bulk } \\
\text { brain does not rule out BMEC } \\
\text { adsorption or incorporation; } 1 \text {. } \\
\text { b Microscopy demonstrated brain } \\
\text { parenchymal fiber entry; } 6\end{array}$ & $0.86(0.17)$ & [113] \\
\hline $\begin{array}{l}\text { 'Ag detected in the brain and } \\
\text { passing through the blood-brain } \\
\text { barrier (i.e., not localized in the } \\
\text { vessels and capillaries) constitutes } \\
\text { no less than } 93 \% \text { of the total } \\
\text { content of } \mathrm{Ag} \text { in the organ' }\end{array}$ & $\begin{array}{l}\text { Silver and gold were determined by NAA in brain of } \\
\text { exsanguinated rats after } 14 \text { or } 28 \text { daily intragastric } \\
\text { administrations of } 35-\mathrm{nm} \text { silver and gold NPs. The authors } \\
\text { calculated brain metal from its concentration in blood and } \\
\text { brain blood mass }\end{array}$ & $\begin{array}{l}\text { This does not account for metal } \\
\text { in BMECs. Silver could be ion } \\
\text { released from NP dissolution. } \\
\text { BBB Ag passage not shown; } 2\end{array}$ & & [14] \\
\hline $\begin{array}{l}\text { 'In vivo studies indicated BBB } \\
\text { penetration of intravenously } \\
\text { injected TIMP-1 NPs + Ps80' }\end{array}$ & $\begin{array}{l}\text { Confocal microscopy ( } 40 \times \text { objective) } \\
\text { immunohistochemistry of brain slices from perfused mice } \\
\text { after iv. injection of polysorbate } 80 \text {-coated coumarin } \\
6 \text {-containing protein-loaded PLGA NPs showed a few } \\
\text { positive spots }\end{array}$ & $\begin{array}{l}\text { Spot location (intra- vs } \\
\text { extravascular) cannot be } \\
\text { determined. BBB penetration not } \\
\text { demonstrated; } 2\end{array}$ & & [114] \\
\hline \multicolumn{5}{|c|}{$\begin{array}{l}\text { Mean residence time from studies that reported brain and blood (in parentheses) levels at multiple times after dosing. Study multiple end points are designated by a, b, c before } \\
\text { the study summary and critique. The level of demonstrated nanoparticle brain entry is from the classification described in Table } 3 \text {. The numbers after the sentences in column } \\
3 \text { refer to the level of demonstrated NP brain entry. } \\
\text { AAS: Atomic absorption spectroscopy; BBB: Blood-brain barrier; BBTB: Blood-brain tumor barrier; BMEC: Brain microvascular endothelial cell; BSA: Bovine serum albumin; CLSM: } \\
\text { Confocal laser scanning microscopy; EDS: Energy dispersive x-ray spectroscopy; EELS: Electron energy loss spectroscopy; FITC: Fluorescein isothiocyanate; ICP-MS: Inductively } \\
\text { coupled plasma-mass spectrometry; ICP-OES: Inductively coupled plasma-optical emission spectroscopy; INAA: Instrumental neutron activation analysis; ip.: Intraperitoneal; iv.: } \\
\text { Intravenous; IVIS: In vivo imaging system; MRT: Mean residence time; MSI: Mass spectrometry imaging; NAA: Neutron activation analysis; NP: Nanoparticle; PBCA: Poly( } n \text {-butyl } \\
\text { cyanoacrylate); RVG: Rabies virus glycoprotein; TEM: Transmission electron microscopy. }\end{array}$} \\
\hline
\end{tabular}


Table 4. Brain nanoparticle distribution study claims, summary, critique, support for the claims and level of brain or brain parenchymal entry. (cont.).

\begin{tabular}{|c|c|c|c|c|}
\hline Claim & Study summary & $\begin{array}{l}\text { Critique, support for claim and } \\
\text { level of demonstrated NP brain } \\
\text { entry }\end{array}$ & MRT (h) & Ref. \\
\hline $\begin{array}{l}\text { 'BBB-penetrating cancer } \\
\text { cell-targeting delivery system' }\end{array}$ & 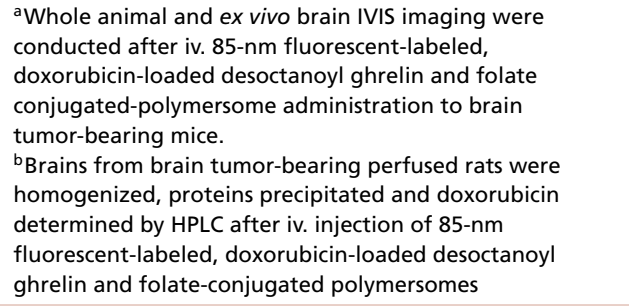 & $\begin{array}{l}\text { a Whole brain results using this } \\
\text { method do not have sufficient } \\
\text { resolution to demonstrate BBB } \\
\text { penetration; } 1 \text {. } \\
{ }^{b} \text { HPLC analysis of NP component } \\
\text { in bulk brain does not } \\
\text { demonstrate BBB penetration; } 2\end{array}$ & & [115] \\
\hline $\begin{array}{l}\text { 'Targeted }{ }^{68} \mathrm{Ga} \text {-GNPs improves } \\
\text { BBB crossing' }\end{array}$ & $\begin{array}{l}\text { Whole brains from perfused rats were gamma counted } \\
\text { after iv. injection of glucose conjugate-coated- }{ }^{68} \mathrm{Ga}-\text { gold } \\
\text { NPs. Brain gold content was determined by ICP-MS }\end{array}$ & $\begin{array}{l}\text { Whole brain radioactivity and } \\
\text { ICP-MS results of NP component } \\
\text { in bulk brain do not verify BBB } \\
\text { crossing; } 2\end{array}$ & & [11] \\
\hline ‘Brain delivery' & $\begin{array}{l}\text { Whole organs were homogenized and Bacoside-A } \\
\text { determined by HPLC after ip. administration of 173-nm } \\
\text { polysorbate } 80 \text {-coated, Bacoside-A-loaded PLGA NPs to } \\
\text { rats }\end{array}$ & $\begin{array}{l}\text { HPLC analysis of NP component } \\
\text { demonstrates bulk brain } \\
\text { delivery; } 1\end{array}$ & & [116] \\
\hline $\begin{array}{l}\text { 'Brain bioavailability of } \\
\text { breviscapine from the } \\
\text { Bre-GBSLN-PS and } \\
\text { Bre-GBSLN-PS-DSPE was } \\
\text { significantly enhanced' }\end{array}$ & $\begin{array}{l}\text { Fifteen kDa cutoff ( } ~ 5 \mathrm{~nm} \text { ) microdialysis probes were used } \\
\text { to obtain dialysate from rat brain after iv. injection of } \\
23-\mathrm{nm} \text { PEG, stearate, 1,2-distearoyl-snglycero-3- } \\
\text { phosphoethanolamine- } N \text {-PEG2000-coated } \\
\text { breviscapine-loaded solid lipid NPs. The primary active } \\
\text { component of breviscapine was measured by HPLC }\end{array}$ & $\begin{array}{l}\text { NP released component does not } \\
\text { identify NP brain location; } 5 \text {, } \\
\text { assuming intact BBB }\end{array}$ & $\begin{array}{l}\text { No decrease } \\
\text { from } 3 \text { to } 12 \mathrm{~h} \\
\text { after } \\
\text { injection (0.61) }\end{array}$ & [76] \\
\hline $\begin{array}{l}\text { 'We ... demonstrated the ability } \\
\text { of these [gelatin NPs] to pass into } \\
\text { the brain parenchyma following } \\
\text { intranasal administration' }\end{array}$ & $\begin{array}{l}\text { SEM of rat brain } 6 \mathrm{~h} \text { after intranasal administration of } \\
184-\mathrm{nm} \text { gelatin NPs showed clusters of approximately } \\
40-\mathrm{nm} \text { spherical particles in the olfactory tract, cortex, } \\
\text { striatum, amygdala and hypothalamus as evidence of NP } \\
\text { brain parenchymal entry }\end{array}$ & $\begin{array}{l}\text { Assuming the observed particles } \\
\text { were gelatin NPs, perhaps } \\
\text { smaller due to tissue processing, } \\
\text { the results suggest brain } \\
\text { parenchymal entry; } 5\end{array}$ & & [117] \\
\hline $\begin{array}{l}\text { 'Migration to brain parenchyma' } \\
\text { 'albumin modulates the } \\
\text { transport across the blood-brain } \\
\text { barrier' }\end{array}$ & $\begin{array}{l}\text { a Whole brain radioactivity was determined by } \\
\text { gamma-scintigraphy of isolated mouse brain after iv. } \\
\text { albumin-coated } 15-\mathrm{nm}{ }^{198} \mathrm{Au} \text { NP injection. } \\
\text { b Brain confocal microscopic images were obtained after iv. } \\
\text { fluorescent-labeled albumin-coated }{ }^{198} \mathrm{Au} \mathrm{NP} \text { injection }\end{array}$ & 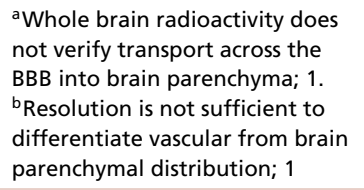 & $21(5.1)$ & [17] \\
\hline $\begin{array}{l}\text { 'Particles that actually crossed } \\
\text { the BBB' }\end{array}$ & $\begin{array}{l}\text { Gold was determined by flame AAS analysis in brain from } \\
\text { mice that received iv. injection of } 20 \text {-nm insulin } \\
\text { PEG-coated gold particles. Brain gold was calculated from } \\
\text { its blood concentration and brain-blood volume }\end{array}$ & $\begin{array}{l}\text { This does not account for gold } \\
\text { associated with BMECs that the } \\
\text { authors hypothesize accounted } \\
\text { for gold in the brain at late time } \\
\text { points; } 1\end{array}$ & $\begin{array}{l}11 \text { (blood did } \\
\text { not decrease } \\
\text { over } 48 \mathrm{~h} \text { ) }\end{array}$ & [118] \\
\hline $\begin{array}{l}\text { 'Coumarin distribution to the } \\
\text { glioma region' }\end{array}$ & $\begin{array}{l}\text { aBrains from glioma-bearing mice were homogenized, } \\
\text { coumarin- } 6 \text { extracted and quantified by HPLC after iv. } \\
\text { injection of } 94-n m \text { coumarin-6, L- } 13 R \alpha 2 \text { ligand-coated } \\
\text { PEG-PLGA NPs. } \\
\text { bFluorescence spots were seen in the brain }\end{array}$ & $\begin{array}{l}{ }^{\text {a } H P L C} \text { analysis of NP component } \\
\text { demonstrates bulk brain } \\
\text { distribution; } 1 \text {. } \\
{ }^{b} \text { Microscopy resolution only } \\
\text { sufficient to demonstrate brain } \\
\text { distribution; } 1\end{array}$ & & [119] \\
\hline 'Brain uptake' & $\begin{array}{l}\text { Radioactivity determined by gamma-scintigraphy of } \\
\text { isolated whole mouse brain after iv. injection of } 9 \text { - and } \\
40-\mathrm{nm} \text { diameter, 396- and } 268-\mathrm{nm} \text { length } \\
{\left[{ }^{111} \mathrm{In}\right]-\mathrm{DTPA}-\mathrm{multiwalled} \text { carbon nanotubes }}\end{array}$ & $\begin{array}{l}\text { Radioactivity demonstrates } \\
\text { distribution of NP or component } \\
\text { in bulk brain; } 1\end{array}$ & & [120] \\
\hline \multicolumn{5}{|c|}{$\begin{array}{l}\text { Mean residence time from studies that reported brain and blood (in parentheses) levels at multiple times after dosing. Study multiple end points are designated by a, b, c before } \\
\text { the study summary and critique. The level of demonstrated nanoparticle brain entry is from the classification described in Table } 3 \text {. The numbers after the sentences in column } \\
3 \text { refer to the level of demonstrated NP brain entry. } \\
\text { AAS: Atomic absorption spectroscopy; BBB: Blood-brain barrier; BBTB: Blood-brain tumor barrier; BMEC: Brain microvascular endothelial cell; BSA: Bovine serum albumin; CLSM: } \\
\text { Confocal laser scanning microscopy; EDS: Energy dispersive x-ray spectroscopy; EELS: Electron energy loss spectroscopy; FITC: Fluorescein isothiocyanate; ICP-MS: Inductively } \\
\text { coupled plasma-mass spectrometry; ICP-OES: Inductively coupled plasma-optical emission spectroscopy; INAA: Instrumental neutron activation analysis; ip.: Intraperitoneal; iv.: } \\
\text { Intravenous; IVIS: In vivo imaging system; MRT: Mean residence time; MSI: Mass spectrometry imaging; NAA: Neutron activation analysis; NP: Nanoparticle; PBCA: Poly( } n \text {-butyl } \\
\text { cyanoacrylate); RVG: Rabies virus glycoprotein; TEM: Transmission electron microscopy. }\end{array}$} \\
\hline
\end{tabular}


Table 4. Brain nanoparticle distribution study claims, summary, critique, support for the claims and level of brain or brain parenchymal entry. (cont.).

\begin{tabular}{|c|c|}
\hline Claim & Study summary \\
\hline $\begin{array}{l}\text { 'Gold would presumably not be } \\
\text { cleared from brain in such a short } \\
\text { timeframe if it has entered the } \\
\text { brain parenchyma' }\end{array}$ & $\begin{array}{l}\text { Brains from mice were digested and gold determined by } \\
\text { ICP-OES after iv. injection of } 80 \text {-nm biodegradable } \\
\text { polymeric micelles with } 5 \mathrm{~nm} \text { gold NP cores }\end{array}$ \\
\hline $\begin{array}{l}\text { 'Demonstrated that the NPs } \\
\text { could cross the BBB' }\end{array}$ & $\begin{array}{l}\text { CLSM images were obtained of brain tissue cryosections, } \\
\text { stained with tomato lectin to label blood vessels, from rat } \\
\text { that received iv. microbubbles and focused ultrasound to } \\
\text { open the BBB before iv. injection of 177-nm fluorescent } \\
\text { dye-containing PBCA NPs }\end{array}$ \\
\hline $\begin{array}{l}\text { 'The peptide was able to diffuse } \\
\text { outside the BBB, while NPs were } \\
\text { restricted to the vessel } \\
\text { endothelium' }\end{array}$ & $\begin{array}{l}\text { CLSM images of brain sections with antibody-stained } \\
\text { BMECs from mice iv. dosed with 35-nm fluorometric } \\
\text { dye-labeled amphiphilic polymer-coated iron oxide NPs } \\
\text { containing a fluorometric dye-labeled antiretroviral drug } \\
\text { enabled distinction among microvessels, NPs and drug. } \\
\text { The NPs and BMECs were co-localized. The antiretroviral } \\
\text { drug was seen within and outside of the vascular } \\
\text { compartment, in brain parenchyma }\end{array}$ \\
\hline
\end{tabular}

'Distributed into the brain tissue' The capillary depletion method was used to obtain a non-BMEC fraction of mouse brains for LC-MS/MS

Critique, support for claim and level of demonstrated NP brain entry

MRT (h)

ICP-OES results of NP component 43 (7.7)

in bulk brain do not show brain parenchymal entry; 1

Fluorescent spots attributed to

the fluorescent dye near the blood vessels suggest NPs crossed the $\mathrm{BBB}$ in the presence of opened BBB; 6

Peptide fluorescence was seen in brain parenchyma; 5 uncoated, chitosan- and $\mathrm{N}$-trimethyl chitosan-coated, curcumin-loaded solid lipid NPs

'BBB penetration by AuNPs'

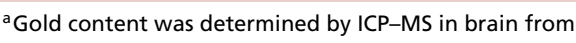
perfused rats that received ip. injection of 1.3-nm gold NPs.

${ }^{\mathrm{b}}$ Gold was determined by laser ablation ICP-MS in brain sections

curcumin was in the supernatan

BMECs, but could have come from blood; 1

${ }^{a}$ ICP-MS results of NP component 8.7 (4.4)

ain do not verify $B B B$

penetration; 2 .

${ }^{b}$ LA-ICP-MS resolution not

sufficient to verify BBB

penetration. 2

AAS results of NP component in bulk brain do not verify BBB crossing; 1

days 1 to 7 'suggested the Iron was quantitated by AAS in solubilized whole organ from mice that received iv. 10-nm carboxyl-coated iron oxide magnetic NPs injection mouse-derived $<50 \mathrm{~nm}$ BMEC exosomes were iv. injected into zebrafish transgenic for vasculature GFP expression drugs crossed the BBB and entered into the brain' 'Nose-to-brain transport' Cyclosporine A was extracted from homogenized olfactory bulb and hind brain samples and quantitated by LC-MS/MS after intranasal dosing of 272-nm nanoemulsion to the rat

‘NPs were capable of penetrating cell membranes and entering cellular compartments'

\section{Brains from mice with green fluorescent}

protein-expressing tumors were imaged using CLSM after Brain parenchymal NP entry

iv. injection of 165-nm fluorescent dye-labeled poly(amineco-ester) terpolymer NPs. PECAM (in BMECs) was labeled. NPs were visualized around tumor blood vessels and within a cell

'Brain accumulation at the site of injury'
Whole-body IVIS images were obtained after iv. administration of approximately $170-\mathrm{nm}$ fluorescent-labeled siRNA-containing biodegradable mesoporous silica, encapsulated in graphene oxide nanosheets. Fluorescence was seen in the hemisphere of mice with damaged brain
CLSM suggests NP fluorescence and shows drug fluorescence outside of the vasculature; 5 LC-MS/MS NP component bulk brain distribution; 1

Greater fluorescence in brain at accumulation; 1

Mean residence time from studies that reported brain and blood (in parentheses) levels at multiple times after dosing. Study multiple end points are designated by ${ }^{a}, b, c$ before the study summary and critique. The level of demonstrated nanoparticle brain entry is from the classification described in Table 3 . The numbers after the sentences in column 3 refer to the level of demonstrated NP brain entry.

AAS: Atomic absorption spectroscopy; BBB: Blood-brain barrier; BBTB: Blood-brain tumor barrier; BMEC: Brain microvascular endothelial cell; BSA: Bovine serum albumin; CLSM: Confocal laser scanning microscopy; EDS: Energy dispersive x-ray spectroscopy; EELS: Electron energy loss spectroscopy; FITC: Fluorescein isothiocyanate; ICP-MS: Inductively coupled plasma-mass spectrometry; ICP-OES: Inductively coupled plasma-optical emission spectroscopy; INAA: Instrumental neutron activation analysis; ip.: Intraperitoneal; iv.: Intravenous; IVIS: In vivo imaging system; MRT: Mean residence time; MSI: Mass spectrometry imaging; NAA: Neutron activation analysis; NP: Nanoparticle; PBCA: Poly(n-butyl cyanoacrylate); RVG: Rabies virus glycoprotein; TEM: Transmission electron microscopy. 
Table 4. Brain nanoparticle distribution study claims, summary, critique, support for the claims and level of brain or brain parenchymal entry. (cont.).

\begin{tabular}{|c|c|c|c|c|}
\hline Claim & Study summary & $\begin{array}{l}\text { Critique, support for claim and } \\
\text { level of demonstrated NP brain } \\
\text { entry }\end{array}$ & MRT (h) & Ref. \\
\hline $\begin{array}{l}\text { 'NP was obviously accumulated in } \\
\text { brain' }\end{array}$ & $\begin{array}{l}\text { Imaging demonstrated mouse whole brain fluorescence } \\
\text { after iv. injection of approximately } 180 \text {-nm cyclic } \\
\text { peptide-modified fluorescence dye-loaded PEG-poly(lactic } \\
\text { acid) NPs }\end{array}$ & $\begin{array}{l}\text { Fluorescence demonstrates brain } \\
\text { accumulation; } 1\end{array}$ & & [124] \\
\hline $\begin{array}{l}\text { 'Delivery of ... NPs across the } \\
\text { blood-brain barrier' }\end{array}$ & $\begin{array}{l}\text { CLSM images of mouse brain after oral administration of } \\
60-\mathrm{nm} \text { PEG-coated, curcumin and piperine-coloaded } \\
\text { glyceryl monooleate NPs showed intracellular NPs }\end{array}$ & $\begin{array}{l}\text { Neuronal intracellular NPs } \\
\text { supports delivery across the } \\
\text { BBB; } 6\end{array}$ & $18(13)$ & [50] \\
\hline $\begin{array}{l}\text { NP were 'taken up into the brain } \\
\text { cells' }\end{array}$ & $\begin{array}{l}\text { Rats with BBB opened by focused ultrasound received iv. } \\
22 \text {-nm fluorescent probe-labeled low-density lipoprotein } \\
\text { NPs. Fluorescence microscopy images were interpreted as } \\
\text { showing punctate fluorescent staining within brain cell } \\
\text { cytosol }\end{array}$ & $\begin{array}{l}\text { Brain parenchymal NP uptake } \\
\text { appears to be shown in the } \\
\text { presence of an opened BBB; } 6\end{array}$ & & [46] \\
\hline 'NP retention in brain tumors' & $\begin{array}{l}\text { aIVIS-imaged whole and ex vivo mouse brain showed } \\
\text { accumulation in glioma after iv. 33-36-nm } \\
\text { fluorescent-labeled, penta-amino acid- or 2-cyano-6-amino } \\
\text { benzothiazole-, or both, coated gold NP injection. } \\
\text { b Glioma were excised for gold quantification by ICP-MS. } \\
\text { 'TEM images showed intracellular densities }\end{array}$ & $\begin{array}{l}{ }^{a} \text { Whole brain results using this } \\
\text { method show NP retention in } \\
\text { brain tumors; } 1 \text {. } \\
\text { bICP-MS NP component in bulk } \\
\text { brain shows brain component } \\
\text { retention; } 1 . \\
\text { 'TEM showed brain parenchymal } \\
\text { NP entry in tumor cells; } 6\end{array}$ & & [125] \\
\hline $\begin{array}{l}\text { ‘Q Quetiapine fumurate]-NP (IV) } \\
\text { may have crossed BBB by } \\
\text { opening tight junctions' }\end{array}$ & $\begin{array}{l}\text { Brains removed from rats were homogenized and } \\
\text { quetiapine quantified by HPLC after iv. injection of } \\
\text { 131-nm quetiapine fumarate-loaded chitosan NPs }\end{array}$ & $\begin{array}{l}\text { HPLC results of NP component in } \\
\text { bulk brain do not verify BBB } \\
\text { crossing; } 1\end{array}$ & $1.5(1.4)$ & [126] \\
\hline $\begin{array}{l}\text { 'Successfully overcame the in vivo } \\
\text { BBB and BBTB delivery barriers' }\end{array}$ & $\begin{array}{l}\text { a Ex vivo brain and dissected tumors from mice with brain } \\
\text { tumors were fluorescent imaged } 4 \mathrm{~h} \text { after iv. injection of } \\
\text { fluorescent dye-loaded cyclic peptide-containing } \\
\text { approximately } 100-\mathrm{nm} \text { liposomes. } \\
\text { b Fluorescent images of brain with fluorescent-stained } \\
\text { microvessels show fluorescence from NPs separate from } \\
\text { microvessels }\end{array}$ & $\begin{array}{l}\text { aWhole brain and tumor } \\
\text { fluorescence does not } \\
\text { demonstrate delivery across the } \\
\text { BBB or BBTB; } 1 \text {. } \\
\text { bSpots of NP fluorescent dye } \\
\text { distinct from blood vessels } \\
\text { suggest NP distribution outside } \\
\text { of brain vasculature; } 5\end{array}$ & & [127] \\
\hline $\begin{array}{l}\text { 'Ex vivo } C T \text { imaging and analysis } \\
\text { indicated that INS-GNPS } \\
\text { transported across the BBB' }\end{array}$ & $\begin{array}{l}\text { a In vivo and ex vivo CT mouse brain imaging was } \\
\text { conducted after iv. } 20-\mathrm{nm} \text { insulin-coated, PEG-layered, } \\
\text { gold NP administration. } \\
{ }^{b} \text { Flame AAS of gold from digested brain was determined }\end{array}$ & $\begin{array}{l}\text { a Whole brain CT images do not } \\
\text { verify transport across the BBB; } 1 \text {. } \\
\text { b AAS results of NP component in } \\
\text { bulk brain do not verify transport } \\
\text { across the BBB; } 1\end{array}$ & $15(18)$ & [128] \\
\hline $\begin{array}{l}\text { 'Brain microvessel endothelial } \\
\text { cell targeting' }\end{array}$ & $\begin{array}{l}\text { Brains of mice were perfused and prepared for } \\
\text { immunohistochemistry and fluorescence imaging after } 2 \\
\text { iv. injections } 1 \mathrm{~h} \text { apart of 50-nm transferrin } \\
\text { antibody-conjugated mesoporous silica NPs. BMECs were } \\
\text { labeled with biotinylated potato lectin detected by } \\
\text { fluorescent-labeled streptavidin. One hour after the } \\
\text { second injection NPs were associated with the BMECs. } \\
\text { There was no evidence brain parenchymal penetration }\end{array}$ & $\begin{array}{l}\text { NP brain microvessel targeting } \\
\text { was demonstrated; } 3\end{array}$ & & [129] \\
\hline $\begin{array}{l}\text { 'Enhanced drug transport across } \\
\text { BBB' }\end{array}$ & $\begin{array}{l}\text { a Iron was determined by AAS in mouse organs after iv. } \\
\text { injection of } 80 \text {-nm dextran-spermine } \\
\text { superparamagnetic-core NPs and } 96-n m \text { transferrin-coated } \\
\text { NPs } \\
\text { b Tissues were stained with Prussian blue to visualize iron } \\
\text { localization }\end{array}$ & $\begin{array}{l}\text { aAAS results of NP component in } \\
\text { bulk brain do not verify transport } \\
\text { across the BBB; } 1 \\
{ }^{\text {b }} \text { Resolution not sufficient to } \\
\text { confirm iron transport across the } \\
\text { BBB; } 1\end{array}$ & $\begin{array}{l}\text { Increased from h } \\
24 \text { to } 168 \text { after } \\
\text { injection }\end{array}$ & [130] \\
\hline \multicolumn{5}{|c|}{$\begin{array}{l}\text { Mean residence time from studies that reported brain and blood (in parentheses) levels at multiple times after dosing. Study multiple end points are designated by a, b, c before } \\
\text { the study summary and critique. The level of demonstrated nanoparticle brain entry is from the classification described in Table } 3 \text {. The numbers after the sentences in column } \\
3 \text { refer to the level of demonstrated NP brain entry. } \\
\text { AAS: Atomic absorption spectroscopy; BBB: Blood-brain barrier; BBTB: Blood-brain tumor barrier; BMEC: Brain microvascular endothelial cell; BSA: Bovine serum albumin; CLSM: } \\
\text { Confocal laser scanning microscopy; EDS: Energy dispersive x-ray spectroscopy; EELS: Electron energy loss spectroscopy; FITC: Fluorescein isothiocyanate; ICP-MS: Inductively } \\
\text { coupled plasma-mass spectrometry; ICP-OES: Inductively coupled plasma-optical emission spectroscopy; INAA: Instrumental neutron activation analysis; ip.: Intraperitoneal; iv.: } \\
\text { Intravenous; IVIS: In vivo imaging system; MRT: Mean residence time; MSI: Mass spectrometry imaging; NAA: Neutron activation analysis; NP: Nanoparticle; PBCA: Poly(n-butyl } \\
\text { cyanoacrylate); RVG: Rabies virus glycoprotein; TEM: Transmission electron microscopy. }\end{array}$} \\
\hline
\end{tabular}


Table 4. Brain nanoparticle distribution study claims, summary, critique, support for the claims and level of brain or brain parenchymal entry. (cont.).

\begin{tabular}{|c|c|c|c|c|}
\hline Claim & Study summary & $\begin{array}{l}\text { Critique, support for claim and } \\
\text { level of demonstrated NP brain } \\
\text { entry }\end{array}$ & MRT (h) & Ref. \\
\hline $\begin{array}{l}\text { 'To further confirm the } \\
\text { translocation of CLS-PEG NPs } \\
\text { across the BBB' } \\
\text { 'C6 to pass through the } \\
\text { blood-brain barrier' }\end{array}$ & $\begin{array}{l}\text { a Rat brains were analyzed by fluorescence analysis after iv. } \\
\text { injection of 176-nm coumarin-6-labeled } \\
\text { cholesterol-containing PBCA NPs and } 185-\mathrm{nm} \text { particles also } \\
\text { containing PEG. } \\
{ }^{\mathrm{b}} \text { Brains from perfused rats were viewed using CLSM that } \\
\text { showed uniform extracellular fluorescence }\end{array}$ & 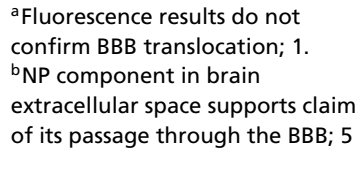 & $\begin{array}{l}2.2 \text { and } 2.3(3.4 \\
\text { and } 5.5)\end{array}$ & [52] \\
\hline $\begin{array}{l}\text { 'The NPs crossed the BBB and } \\
\text { entered the brainparenchyma' }\end{array}$ & 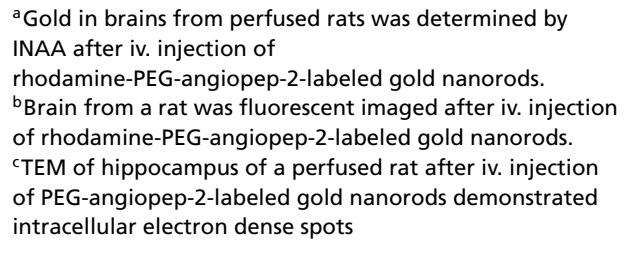 & $\begin{array}{l}\text { aINAA results of NP component } \\
\text { in bulk brain does not } \\
\text { demonstrate distribution across } \\
\text { the BBB; } 1 \text {. } \\
\text { b Fluorescence results do not } \\
\text { confirm BBB translocation; } 1 . \\
\text { 'NP seen in brain parenchyma; } 6 \text {, } \\
\text { assuming the spots were gold } \\
\text { nanorods }\end{array}$ & & [131] \\
\hline 'Brain delivery' & $\begin{array}{l}\text { Brains from mice were homogenized for LC/MS RU } \\
\text { determination after iv. injection of marigold flower } \\
\text { extract (RU)-, polysorbate-80-containing lipid polymer } \\
\text { hybrid PLGA NPs }\end{array}$ & $\begin{array}{l}\text { LC/MS results of NP component } \\
\text { support bulk brain delivery; } 1\end{array}$ & $2.5(1.2)$ & [132] \\
\hline $\begin{array}{l}\text { ‘Uptake by neuronal cells and } \\
\text { appreciable crossing of } \\
\text { blood-brain barrier' }\end{array}$ & $\begin{array}{l}\text { Brains from rats were homogenized, solvent extracted and } \\
\text { dimethyl fumarate determined by HPLC after oral } \\
\text { administration of dimethyl fumarate-containing solid lipid } \\
\text { NPs }\end{array}$ & $\begin{array}{l}\text { HPLC results of NP component in } \\
\text { bulk brain do not verify neuronal } \\
\text { cell uptake or BBB crossing; } 1\end{array}$ & $5.7(4.7)$ & [133] \\
\hline 'Lamotrigine brain uptake' & $\begin{array}{l}\text { Lamotrigine was determined by HPLC in homogenized } \\
\text { brain after iv. injection of } 125 \text {-nm lamotrigine-loaded } \\
\text { poly- } \varepsilon \text {-(D,L-lactide-co-caprolactone) NPs }\end{array}$ & $\begin{array}{l}\text { HPLC results of NP component } \\
\text { show bulk brain uptake; } 1\end{array}$ & & [134] \\
\hline $\begin{array}{l}\text { ‘[DNA-coated gold NPs] can be } \\
\text { successfully delivered to specific } \\
\text { brain locations across the BBB in } \\
\text { mice using focused ultrasound' }\end{array}$ & $\begin{array}{l}\text { Mice were iv. injected with 6-14-nm fluorescent-labeled } \\
\text { DNA-coated gold NPs after unilateral microbubble } \\
\text { injection and before ultrasound to open the BBB. The } \\
\text { effected hemisphere showed more NPs (bright-field and } \\
\text { fluorescence microscopy) than the contralateral } \\
\text { hemisphere }\end{array}$ & $\begin{array}{l}\text { Resolution was not sufficient to } \\
\text { verify delivery across the BBB; } 1\end{array}$ & & [135] \\
\hline $\begin{array}{l}\text { 'This strategy increased NP } \\
\text { translocation into brain } \\
\text { parenchyma' }\end{array}$ & $\begin{array}{l}\text { CLSM of brain, stained for GFAP to localize astrocyte foot } \\
\text { processes, from mice iv. injected with 180-nm } \\
\text { ApoE4-coated, fluorescent dye-labeled, lipid, } \\
\text { polysorbate- } 80 \text { NPs showed some fluorescence from the } \\
\text { NPs not surrounded by fluorescence from GFAP }\end{array}$ & $\begin{array}{l}\text { Fluorescence from the NP label } \\
\text { appears to be in brain } \\
\text { parenchyma; } 5\end{array}$ & & [25] \\
\hline $\begin{array}{l}\text { 'Gamma scintigraphicimages } \\
\text { showed } \ldots \text { the radiolabeled } \\
\text { formulations successfully crossed } \\
\text { BBB' }\end{array}$ & $\begin{array}{l}\text { a Whole rat gamma scintigraphy was conducted after iv. } \\
\text { injection of } 24-\mathrm{nm} \text { AZT-containing }{ }^{99 \mathrm{~m}} \text { Tc-labeled } \\
\text { nanoliposomes. } \\
{ }^{\mathrm{b}} \text { AZT was determined by HPLC in homogenized brain of in } \\
\text { situ blood-perfused rats after iv. injection of } 24 \mathrm{~nm} \\
\text { AZT-containing }{ }^{99 \mathrm{~m}} \text { Tc-labeled nanoliposomes }\end{array}$ & 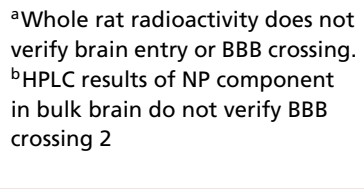 & $6.2(8.8)$ & [136] \\
\hline $\begin{array}{l}\text { 'Blood-brain barrier permeability } \\
\text { of the NPs was successfully } \\
\text { demonstrated by the } \\
\text { incorporation of fluorescent dye, } \\
\text { Rhodamine B in the NPs' }\end{array}$ & $\begin{array}{l}\text { Brain from rats was homogenized, solvent extracted and } \\
\text { Rhodamine B determined by HPLC after ip. injection of } \\
300-400-n m \text { saxagliptin-loaded chitosan-L-valine-based } \\
\text { NPs }\end{array}$ & $\begin{array}{l}\text { HPLC results of NP component in } \\
\text { bulk brain do not verify BBB } \\
\text { permeability; } 1\end{array}$ & & [137] \\
\hline $\begin{array}{l}\text { 'Brain accumulation of } \\
\text { curcumin-loaded NPs' }\end{array}$ & $\begin{array}{l}\text { Fluorescence in homogenized brains from perfused rats } \\
\text { was determined byHPLC after iv. injection of } 46-\mathrm{nm} \\
\text { 6-coumarin-loaded oleic acid-conjugated } \\
\text { PEG-poly( } \varepsilon \text {-caprolactone) NPs }\end{array}$ & $\begin{array}{l}\text { HPLC results of NP component } \\
\text { show bulk brain delivery; } 2\end{array}$ & & [138] \\
\hline \multicolumn{5}{|c|}{$\begin{array}{l}\text { Mean residence time from studies that reported brain and blood (in parentheses) levels at multiple times after dosing. Study multiple end points are designated by a, b, c before } \\
\text { the study summary and critique. The level of demonstrated nanoparticle brain entry is from the classification described in Table } 3 \text {. The numbers after the sentences in column } \\
3 \text { refer to the level of demonstrated NP brain entry. } \\
\text { AAS: Atomic absorption spectroscopy; BBB: Blood-brain barrier; BBTB: Blood-brain tumor barrier; BMEC: Brain microvascular endothelial cell; BSA: Bovine serum albumin; CLSM: } \\
\text { Confocal laser scanning microscopy; EDS: Energy dispersive x-ray spectroscopy; EELS: Electron energy loss spectroscopy; FITC: Fluorescein isothiocyanate; ICP-MS: Inductively } \\
\text { coupled plasma-mass spectrometry; ICP-OES: Inductively coupled plasma-optical emission spectroscopy; INAA: Instrumental neutron activation analysis; ip.: Intraperitoneal; iv.: } \\
\text { Intravenous; IVIS: In vivo imaging system; MRT: Mean residence time; MSI: Mass spectrometry imaging; NAA: Neutron activation analysis; NP: Nanoparticle; PBCA: Poly(n-butyl } \\
\text { cyanoacrylate); RVG: Rabies virus glycoprotein; TEM: Transmission electron microscopy. }\end{array}$} \\
\hline
\end{tabular}


Table 4. Brain nanoparticle distribution study claims, summary, critique, support for the claims and level of brain or brain parenchymal entry. (cont.).

\begin{tabular}{|c|c|c|c|c|}
\hline Claim & Study summary & $\begin{array}{l}\text { Critique, support for claim and } \\
\text { level of demonstrated NP brain } \\
\text { entry }\end{array}$ & MRT (h) & Ref. \\
\hline $\begin{array}{l}\text { 'After intravenous } \\
\text { administration, fluorescent [solid } \\
\text { lipid NPs] were detected in brain } \\
\text { parenchyma outside the vascular } \\
\text { bed, confirming their ability to } \\
\text { overcome the BBB' }\end{array}$ & $\begin{array}{l}\text { Epi-fluorescence microscopy of rat brain } 24 \mathrm{~h} \text { after iv. } \\
\text { injection of } 278 \text {-nm FITC and Brij } 78 \text {-containing solid lipid } \\
\text { NPs showed spherical fluorescence not associated with an } \\
\text { endothelial marker }\end{array}$ & $\begin{array}{l}\text { Spherical fluorescence in absence } \\
\text { of blood vessel marker } \\
\text { fluorescence suggests NP brain } \\
\text { parenchymal entry; } 5\end{array}$ & & [139] \\
\hline $\begin{array}{l}\text { 'Ex vivo imaging and } \\
\text { semiquantitative assay of the } \\
\text { brains demonstrated the brain } \\
\text { penetrating behavior of ... NPs' }\end{array}$ & $\begin{array}{l}{ }^{a} \text { Whole mice were multispectral and ex vivo brain CLSM } \\
\text { imaged after iv. injection of 148-nm menthol BSA NPs. } \\
{ }^{b} \text { CLSM and TEM images were obtained of the pineal gland } \\
\text { (which lacks a BBB) of rats after iv. 148-nm menthol BSA } \\
\text { silver NP injection }\end{array}$ & $\begin{array}{l}\text { aWhole-body multispectral and } \\
\text { CLSM imaging show bulk brain } \\
\text { delivery; } 1 \text {. } \\
\text { bTEM shows one electron dense } \\
\text { spot. Its chemical composition } \\
\text { was not reported; } 6 \text {, assuming } \mathrm{Ag} \\
\text { in the spot }\end{array}$ & & [53] \\
\hline $\begin{array}{l}\text { 'Bioavailability of quercetin in } \\
\text { the brain' }\end{array}$ & $\begin{array}{l}\text { Brains from rats were homogenized, proteins precipitated } \\
\text { and quercetin determined by HPLC after oral feeding of } \\
30-50-n m \text { quercetin-coated superparamagnetic iron oxide } \\
\text { NPs }\end{array}$ & $\begin{array}{l}\text { HPLC results of NP component } \\
\text { show bulk brain delivery; } 1\end{array}$ & & [140] \\
\hline 'Brain distribution/delivery' & $\begin{array}{l}\text { Brains from rats were homogenized, proteins precipitated } \\
\text { and rivastigmine determined by HPLC after iv. injection of } \\
\text { 145-nm rivastigmine-loaded mesoporous silica NPs }\end{array}$ & $\begin{array}{l}\text { HPLC results of NP component } \\
\text { show bulk brain delivery; } 1\end{array}$ & 6.5 & [141] \\
\hline $\begin{array}{l}\text { 'Penetration of NPs into brain } \\
\text { parenchyma' }\end{array}$ & $\begin{array}{l}\text { Three adjacent sections from isolated guinea pig brains } \\
\text { were assessed bysilver-enhanced brightfield microscopy, } \\
\text { CLSM and TEM after arterial perfusionfor } 120 \text { min of } \\
\text { approximately } 8 \mathrm{~nm} \text { fluorescent-labeled } \\
\text { mercaptoundecylsulfonic acid/octanethiol coated } \\
\text { gold/iron core NPs followed by 30-min washout perfusion }\end{array}$ & $\begin{array}{l}\text { CLSM indicates fluorescence } \\
\text { surrounding cell nuclei. Optical } \\
\text { microscopy shows silver stain } \\
\text { surrounding blood vessels. TEM } \\
\text { shows electron dense particles on } \\
\text { the luminal wall of BMECs and } \\
\text { inside brain cells; } 6\end{array}$ & & [22] \\
\hline $\begin{array}{l}\text { NPs 'passed the BBB, and entered } \\
\text { the cytoplasm of vascular } \\
\text { endothelial cells, as depicted by } \\
\text { the biodistribution studies, flow } \\
\text { cytometry analysis and } \\
\text { subcellular TEM micrographs.' }\end{array}$ & $\begin{array}{l}\text { a Brains from perfused mice were homogenized and cells } \\
\text { analyzed by flow cytometry } 1 \mathrm{~h} \text { after ip. injection of } \\
\text { fluorescent-labeled glucose- or PEG-glucose-coated silica } \\
\text { NPs. } \\
\text { b Brains from perfused mice were CLSM imaged } 1 \mathrm{~h} \text { after } \\
\text { ip. injection of fluorescent-labeled glucose- or } \\
\text { PEG-glucose-coated silica NPs. } \\
\text { 'Brains harvested from mice were TEM imaged } 1 \mathrm{~h} \text { after } \\
\text { ip. injection of fluorescent-labeled PEG-glucose-coated } \\
\text { silica NPs }\end{array}$ & 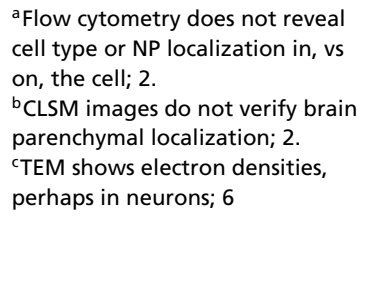 & & [54] \\
\hline $\begin{array}{l}\text { 'NP formulation increased BBB } \\
\text { transport ... in vivo' }\end{array}$ & $\begin{array}{l}\text { a Whole mouse fluorescence imaging was conducted from } \\
0.25 \text { to } 24 \mathrm{~h} \text { after intranasal dosing of indocyanine green } \\
\text { containing transferrin or RVG-coated BSA NPs. } \\
\text { b Oxytocin in CSF was determined by enzyme-linked } \\
\text { immunosorbent assay after intranasal dosing of } \\
\text { oxytocin-containing RVG-coated BSA NPS }\end{array}$ & $\begin{array}{l}\text { a Whole body bioimaging does } \\
\text { not verify BBB transport; } 1 . \\
{ }^{b} \text { NP component in CSF does not } \\
\text { demonstrate brain uptake }\end{array}$ & 7.4 & [82] \\
\hline $\begin{array}{l}\text { 'Enhanced delivery of } \\
\text { [doxorubicin] across the BBB' }\end{array}$ & $\begin{array}{l}\text { HPLC of dialysates from microdialysis of rat hippocampus } \\
\text { after intranasal dosing of } 92-n m \text { polysaccharide NP } \\
\text { containing doxorubicin showed doxorubicin concentration } \\
\text { peak at } 30 \mathrm{~min}\end{array}$ & $\begin{array}{l}\text { Peak doxorubicin concentration } \\
\text { this soon cannot be due to nose } \\
\text { to hippocampus neuronal } \\
\text { transport. It would be } \\
\text { distribution across the BBB. NP } \\
\text { component does not } \\
\text { demonstrate brain NP uptake; } 1\end{array}$ & 4.2 & [77] \\
\hline
\end{tabular}

Mean residence time from studies that reported brain and blood (in parentheses) levels at multiple times after dosing. Study multiple end points are designated by ${ }^{a, b}, \mathrm{c}$ before the study summary and critique. The level of demonstrated nanoparticle brain entry is from the classification described in Table 3 . The numbers after the sentences in column 3 refer to the level of demonstrated NP brain entry.

AAS: Atomic absorption spectroscopy; BBB: Blood-brain barrier; BBTB: Blood-brain tumor barrier; BMEC: Brain microvascular endothelial cell; BSA: Bovine serum albumin; CLSM: Confocal laser scanning microscopy; EDS: Energy dispersive x-ray spectroscopy; EELS: Electron energy loss spectroscopy; FITC: Fluorescein isothiocyanate; ICP-MS: Inductively coupled plasma-mass spectrometry; ICP-OES: Inductively coupled plasma-optical emission spectroscopy; INAA: Instrumental neutron activation analysis; ip.: Intraperitoneal; iv.: Intravenous; IVIS: In vivo imaging system; MRT: Mean residence time; MSI: Mass spectrometry imaging; NAA: Neutron activation analysis; NP: Nanoparticle; PBCA: Poly(n-butyl cyanoacrylate); RVG: Rabies virus glycoprotein; TEM: Transmission electron microscopy. 
Table 4. Brain nanoparticle distribution study claims, summary, critique, support for the claims and level of brain or brain parenchymal entry. (cont.).

\begin{tabular}{|c|c|c|c|c|}
\hline Claim & Study summary & $\begin{array}{l}\text { Critique, support for claim and } \\
\text { level of demonstrated NP brain } \\
\text { entry }\end{array}$ & MRT (h) & Ref. \\
\hline $\begin{array}{l}\text { '[NP] rapidly and effectively } \\
\text { delivered drugs to the brain via } \\
\text { the nose-to-brain pathway' }\end{array}$ & $\begin{array}{l}\text { Mouse brain was IVIS imaged ex vivo and MRI imaged } \\
\text { after intranasal dosing of } 110 \text { - or } 143-\mathrm{nm} \text { fluorescent and } \\
\text { gadolinium-labeled cholera toxin or BSA NP }\end{array}$ & $\begin{array}{l}\text { Whole brain results using these } \\
\text { methods show fluorescence and } \\
\text { gadolinium in the brain; } 1\end{array}$ & 11.6 & [142] \\
\hline 'NP delivery to the brain' & $\begin{array}{l}\text { Ex vivo brain was IVIS imaged after iv. injection of } \\
\text { fluorescent-labeled, microbubble complexed, albumin NPS } \\
\text { and ultrasound to brain tumor bearing mice }\end{array}$ & $\begin{array}{l}\text { Whole brain results using this } \\
\text { method show fluorescence in the } \\
\text { brain; } 1\end{array}$ & & [143] \\
\hline $\begin{array}{l}\text { NP 'transport across the BBB } \\
\text { after intravenous administration' }\end{array}$ & $\begin{array}{l}\text { CLSM images are claimed to show } 140-200-n m \\
\text { phosphatidic and sialic acid, } \\
\text { 5-hydroxytryptamine-moduline modified PLGA NPs in the } \\
\text { hippocampus of rats after their iv. injection }\end{array}$ & $\begin{array}{l}\text { No fluorescence attributed to the } \\
\text { NPs can be seen }\end{array}$ & & [55] \\
\hline $\begin{array}{l}\text { ‘BBB penetration and NP } \\
\text { distribution into brain } \\
\text { parenchyma' }\end{array}$ & $\begin{array}{l}\text { Epifluorescence was determined in brain regions that did } \\
\text { not contain vasculature after iv. injection of 4-nm } \\
\text { Angiopep-2, transferrin receptor ligand, endosome escape } \\
\text { unit, fluorescent marker containing malic acid NPs in mice } \\
\text { whose cerebrovascular was stained. The results were } \\
\text { interpreted to indicate that the NPs traversed the BBB and } \\
\text { approximately } 40 \% \text { of plasma fluorescence was in the } \\
\text { parenchyma with the highest concentration proximal to } \\
\text { the vasculature }\end{array}$ & $\begin{array}{l}\text { The methods suggest the } \\
\text { fluorescent component of the NP } \\
\text { entered brain parenchyma; } 5\end{array}$ & & [144] \\
\hline $\begin{array}{l}\text { ‘[NP] crossing intact BBB was ... } \\
\text { demonstrated in healthy mice' }\end{array}$ & $\begin{array}{l}\text { Confocal microscopy of mouse brain after iv. injection of } \\
126-n m \text { doxorubicin, mitomycin C and internalizing } \\
\text { peptide-labeled terpolymer-lipid hybrid NP after iv. } \\
\text { injection of Texas-red-dextran to visualize blood vessels } \\
\text { showed particulate doxorubicin fluorescence not } \\
\text { associated with blood vessels }\end{array}$ & $\begin{array}{l}\text { Punctate fluorescence attributed } \\
\text { to doxorubicin not associated } \\
\text { with blood vessels suggests brain } \\
\text { parenchymal NP entry; } 6\end{array}$ & & [145] \\
\hline \multicolumn{5}{|c|}{$\begin{array}{l}\text { Mean residence time from studies that reported brain and blood (in parentheses) levels at multiple times after dosing. Study multiple end points are designated by a, b, c before } \\
\text { the study summary and critique. The level of demonstrated nanoparticle brain entry is from the classification described in Table } 3 \text {. The numbers after the sentences in column } \\
3 \text { refer to the level of demonstrated NP brain entry. } \\
\text { AAS: Atomic absorption spectroscopy; BBB: Blood-brain barrier; BBTB: Blood-brain tumor barrier; BMEC: Brain microvascular endothelial cell; BSA: Bovine serum albumin; CLSM: } \\
\text { Confocal laser scanning microscopy; EDS: Energy dispersive x-ray spectroscopy; EELS: Electron energy loss spectroscopy; FITC: Fluorescein isothiocyanate; ICP-MS: Inductively } \\
\text { coupled plasma-mass spectrometry; ICP-OES: Inductively coupled plasma-optical emission spectroscopy; INAA: Instrumental neutron activation analysis; ip.: Intraperitoneal; iv.: } \\
\text { Intravenous; IVIS: In vivo imaging system; MRT: Mean residence time; MSI: Mass spectrometry imaging; NAA: Neutron activation analysis; NP: Nanoparticle; PBCA: Poly(n-butyl } \\
\text { cyanoacrylate); RVG: Rabies virus glycoprotein; TEM: Transmission electron microscopy. }\end{array}$} \\
\hline
\end{tabular}

dependent, increasing from less than $96 \mathrm{~h}$ after $60 \mu \mathrm{g}$ to approximately $480 \mathrm{~h}$ after $1600 \mu \mathrm{g}$ [81], suggesting the quantity of NPs in brain parenchyma influence their duration of persistence in that compartment.

Some studies reported the brain level of the NP or its components at multiple times after its peripheral administration. Some studies also reported blood and/or peripheral organ levels. The reported values are shown in Supplementary Figure 1. To be able to visually compare the rates of $\mathrm{NP} /$ component increase or decrease over time given the wide range of levels and timecourses among the studies, the results were normalized to the dose for CED studies or first reported value for other studies and shown as double log figures. It is expected that NPs that entered brain parenchyma would persist longer in the brain than NPs that did not cross the BBB, and longer than in the blood. Most reports of brain NP or component determination over time did not have many values (range for the non-CED and non-microdialysis studies: $2-16$, median: 5) discouraging rigorous pharmacokinetic analysis or estimate of NP residence to infinity. Noncompartmental mean residence time (MRT) to the last sample was determined using Phoenix 8.1 WinNonLin. The MRT of NPs or their components after peripheral or intranasal administration is generally less than after CED, suggesting less than $100 \%$ of the NPs or components entered brain parenchyma. Good agreement was obtained between the MRT results and author reported half-lives for the same datasets (Tables $1 \& 4$ ). The MRT was similarly calculated for NP, or its component, in blood from the studies that determined them at multiple times after NP administration. The results are shown in parentheses in Table 4. The timecourse and MRTs for the NP or its component in the brain, blood and peripheral organs were often similar (Supplementary Figure $1 \&$ Table 4). This could be due to most or all of the NP/component in the brain residing in blood within the brain or adhering to the luminal wall of BMECs and being cleared from brain at the same rate as blood clearance from peripheral circulation. Exceptions were seen in two reports where the brain MRT was considerably longer than blood MRT [17,58], suggesting NP distribution beyond the vascular compartment. However, evidence of brain parenchymal entry was not provided. 
Studies classified according to the criteria in Table 3 as demonstrating brain parenchymal entry (levels 5 and 6 ) that reported brain NP or component levels at multiple times are shown in Supplementary Figure 1D and E. Brain levels often increased over time or decreased more slowly than in studies classified as not showing brain parenchymal entry. Brain levels often decreased more slowly than blood levels in studies shown in Supplementary Figure 1D $\& \mathrm{E}$ than $\mathrm{B}$ or $\mathrm{C}$. There is some concordance between the classification levels and $\mathrm{NP} /$ component timecourse in the brain, suggesting the rate of $\mathrm{NP} /$ component clearance from the brain reflects the absence or presence of brain parenchymal entry.

The evidence of NP parenchymal entry may not be from the same measure as that providing the brain timecourse (e.g., TEM showing NP in brain cells, whereas NP/marker residence determined by HPLC). When NP or component was determined by radioactivity, neutron activation analysis, IVIS imaging, fluorescence, HPLC, atomic absorption spectroscopy, inductively coupled plasma-optical emission spectroscopy, inductively coupled plasma-mass spectrometry or LC-MS, it could be that only a fraction was in brain parenchyma. A risk of concluding NP brain entry or brain parenchymal entry from a component of the NP, such as an incorporated fluorescent dye or a metal component of a metal- or metal oxide-containing NP, is that the dye or metal might be released and its distribution does not represent the NP. For example, it was concluded that dye clearance from the brain in $24 \mathrm{~h}$ was 'most likely due to degradation of the dye itself rather than actual clearance of the NPs from the brain' [82]. Similarly, metal analysis by neutron activation analysis, atomic absorption spectroscopy, inductively coupled plasma-optical emission spectroscopy or inductively coupled plasma-mass spectrometry may be informing about released ion, particularly from readily soluble NPs such as those containing copper, silver and zinc.

In contrast, the results of many studies which did not demonstrate NP distribution in brain parenchyma showed more rapid clearance of brain-associated NPs (Table $4 \&$ Supplementary Figure 1). Many studies did not remove blood from the brain. The decline of NPs within a few hours in the brain, at a rate similar to its decline in blood, and more rapidly than the decline from peripheral organs, may be due to lack of brain parenchymal entry. Such results suggest that only some, or none, of the NPs crossed the BBB. The NPs may have adhered to the luminal wall of brain vasculature or localized in cellular or membrane components of the BBB, and subsequently distributed away from these sites into blood circulating through the brain. In studies that did not use sufficient methods to demonstrate NP brain parenchymal entry, the NPs may indeed have crossed the BBB. However, the methods do not verify that. If procedures are used to rule out the contribution of NPs in blood and adherence to BMECs, NP persistence in the brain may indicate successful distribution across the BBB.

\section{Conclusion}

The BBB and BCSFB provide a significant challenge to deliver substances into the brain to access neural, glial and cancer cells. Verification that the substance has entered into the compartment that houses these cells (brain parenchyma) is not trivial. Experimental results are sometimes overinterpreted to suggest successful delivery of substances that might directly act on cells in the brain when verification of brain parenchymal entry is lacking. An understanding of the anatomy and location of the barriers (BBB and BCSFB) to brain parenchymal entry helps one interpret if a substance has entered brain parenchyma. Visual and procedural methods have been used to verify brain parenchymal entry. In this article, methods have been classified as to the level of verification of brain parenchymal entry and then critically applied to studies. The BBB can be bypassed by direct substance introduction into the brain by CED that often results in prolonged residence of the substance in the brain. It is suggested that prolonged substance residence in the brain after its peripheral (e.g., iv.) administration suggests brain parenchymal entry. It is hoped that this guide will help researchers and reviewers be more precise in their demonstration and interpretation of substance distribution in the brain.

\section{Future perspective}

As the study of NP biological interaction matures, there is greater understanding of how to critically assess NP effects and their distribution. If the criteria and methods that demonstrate bulk brain and brain parenchymal entry proposed herein are employed by researchers and reviewers, there will be more precise reporting of brain NP distribution. More realistic result interpretation will enable more realistic clinical benefit expectation. This will enhance the credibility of this endeavor and help investigators engage in best practice research. 
Supplementary data

To view the supplementary data that accompany this paper please visit the journal website at: www.futuremedicine.com/doi/suppl/10.2217/nnm-2019-0169

Acknowledgments

The author thanks Uschi M Graham for her excellent suggestion on the tenor of this review and suggestion of some of the reviews cited in Table 1, and Matt Hazzard, medical illustrator, University of Kentucky College of Medicine for creating Figure 1.

Financial \& competing interests disclosure

The author has no relevant affiliations or financial involvement with any organization or entity with a financial interest in or financial conflict with the subject matter or materials discussed in the manuscript. This includes employment, consultancies, honoraria, stock ownership or options, expert testimony, grants or patents received or pending or royalties.

No writing assistance was utilized in the production of this manuscript.

\section{Open access}

This work is licensed under the Attribution-NonCommercial-NoDerivatives 4.0 Unported License. To view a copy of this license, visit http://creativecommons.org/licenses/by-nc-nd/4.0/

\section{Executive summary}

- The anatomy and function of the blood-brain (BBB) and blood-cerebrospinal fluid barriers are reviewed.

- Exposure routes to bypass the BBB (convection-enhanced delivery and uptake from the nasal cavity by cranial nerves) are described.

- Visual and procedural methods to determine nanoparticle (NP) brain and brain parenchymal entry are presented.

- Criteria are proposed to classify levels of experimental result evidence that demonstrate NP bulk brain or brain parenchymal entry.

- Studies of NP brain entry or distribution across the BBB are summarized, critiqued and evaluated using the classification levels to interpret if the study shows NP bulk brain or brain parenchymal entry.

- NP or component persistence in the brain after systemic or intranasal administration compared with blood and peripheral organs and direct infusion by convection-enhanced delivery into the brain are compared with interpret support for NP distribution beyond the brain vasculature, into brain parenchyma.

\section{References}

Papers of special note have been highlighted as: $\bullet$ of interest; $\bullet \bullet$ of considerable interest

1. Sanovich E, Bartus RT, Friden PM et al. Pathway across blood-brain barrier opened by the bradykinin agonist, RMP-7. Brain Res. 705(1-2), 125-135 (1995).

2. Burke MJC, Nelson L, Slade JY et al. Morphometry of the hippocampal microvasculature in post-stroke and age-related dementias. Neuropathol. Appl. Neurobiol. 40(3), 284-295 (2014).

3. Zlokovic BV, Apuzzo ML. Strategies to circumvent vascular barriers of the central nervous system. Neurosurgery 43(4), 877-878 (1998).

-. The figure in this report shows the blood vessels in the human brain, illustrating their presence throughout the brain.

4. Boström M, Hellstroem Erkenstam N, Kaluza D et al. The hippocampal neurovascular niche during normal development and after irradiation to the juvenile mouse brain. Int. J. Radiat. Biol. 90(9), 778-789 (2014).

5. Ohno K, Pettigrew KD, Rapoport SI. Lower limits of cerebrovascular permeability to nonelectrolytes in the conscious rat. Am. J. Physiol. 235(3), H299-H307 (1978).

- The blood volumes in brain regions are reported.

6. Calvo P, Gouritin B, Chacun H et al. Long-circulating PEGylated polycyanoacrylate nanoparticles as new drug carrier for brain delivery. Pharm. Res. 18(8), 1157-1166 (2001).

7. Weiss N, Miller F, Cazaubon S, Couraud P-O. The blood-brain barrier in brain homeostasis and neurological diseases. Biochim. Biophys. Acta, Biomembr. 1788(4), 842-857 (2009).

8. Rosenberg GA. Neurological diseases in relation to the blood-brain barrier. J. Cereb. Blood Flow Metab. 32(7), 1139-1151 (2012).

9. Bellavance M-A, Blanchette M, Fortin D. Recent advances in blood-brain barrier disruption as a CNS delivery strategy. AAPS J. 10(1), 166-177 (2008).

10. Burgess A, Hynynen K. Microbubble-assisted ultrasound for drug delivery in the brain and central nervous system. Adv. Exp. Med. Biol. 880, 293-308 (2016). 
11. Frigell J, Garcia I, Gomez-Vallejo V, Llop J, Penades S. ${ }^{68}$ Ga-labeled gold glyconanoparticles for exploring blood-brain barrier permeability: preparation, biodistribution studies, and improved brain uptake via neuropeptide conjugation. J. Am. Chem. Soc. 136(1), 449-457 (2014).

- Demonstration that nanoparticles (NPs) in blood within the brain can have a considerable contribution to bulk brain NPs.

12. Sela H, Elia P, Zach R et al. Spontaneous penetration of gold nanoparticles through the blood brain barrier (BBB). J. Nanobiotechnol. 13, 71 (2015).

13. Gage GJ, Kipke DR, Shain W. Whole animal perfusion fixation for rodents. J. Vis. Exp. 65(65), 3564 (2012).

- A perfusion method to remove blood from the brain.

14. Buzulukov YP, Arianova EA, Demin VF et al. Bioaccumulation of silver and gold nanoparticles in organs and tissues of rats studied by neutron activation analysis. Biol. Bull. 41(3), 255-263 (2014).

15. Schleh C, Semmler-Behnke M, Lipka J et al. Size and surface charge of gold nanoparticles determine absorption across intestinal barriers and accumulation in secondary target organs after oral administration. Nanotoxicology 6, 36-46 (2012).

16. Yokel RA, Tseng MT, Dan M et al. Biodistribution and biopersistence of ceria engineered nanomaterials: size dependence. Nanomedicine 9(3), 398-407 (2013).

17. Schäffler M, Sousa F, Wenk A et al. Blood protein coating of gold nanoparticles as potential tool for organ targeting. Biomaterials 35(10), 3455-3466 (2014).

18. Hirn S, Semmler-Behnke M, Schleh C et al. Particle size-dependent and surface charge-dependent biodistribution of gold nanoparticles after intravenous administration. Eur. J. Pharm. Biopharm. 77(3), 407-416 (2011).

19. Gessner A, Olbrich C, Schroder W, Kayser O, Muller RH. The role of plasma proteins in brain targeting: species dependent protein adsorption patterns on brain-specific lipid drug conjugate (LDC) nanoparticles. Int. J. Pharm. 214(1-2), 87-91 (2001).

20. Baghirov H, Karaman D, Viitala T et al. Feasibility study of the permeability and uptake of mesoporous silica nanoparticles across the blood-brain barrier. PLoS ONE 11(8), e0160705 (2016).

21. Dan M, Tseng MT, Wu P et al. Brain microvascular endothelial cell association and distribution of a $5 \mathrm{~nm}$ ceria engineered nanomaterial. Int. J. Nanomed. 7, 4023-4036 (2012).

- An electron micrograph figure showing NPs adhering to the luminal wall of brain microvascular endothelial cells after perfusion to remove blood from the brain.

22. Sanavio B, Librizzi L, Pennacchio P et al. Distribution of superparamagnetic Au/Fe nanoparticles in an isolated guinea pig brain with an intact blood brain barrier. Nanoscale 10(47), 22420-22428 (2018).

23. Wilhelm C, Gazeau F, Roger J, Pons JN, Bacri JC. Interaction of anionic superparamagnetic nanoparticles with cells: kinetic analyses of membrane adsorption and subsequent internalization. Langmuir 18(21), 8148-8155 (2002).

24. Fiandra L, Colombo M, Mazzucchelli $S$ et al. Nanoformulation of antiretroviral drugs enhances their penetration across the blood brain barrier in mice. Nanomedicine 11(6), 1387-1397 (2015).

-• One of the best demonstrations differentiating NP and NP component distribution within and not within brain parenchyma.

25. Dal Magro R, Albertini B, Beretta S et al. Artificial apolipoprotein corona enables nanoparticle brain targeting. Nanomedicine 14(2), 429-438 (2018).

-• One of the best demonstrations differentiating NP and NP component distribution within and not within brain parenchyma.

26. Healy AT, Vogelbaum MA. Convection-enhanced drug delivery for gliomas. Surg. Neurol. Int. 6(Suppl. 1), S59-S67 (2015).

27. Lonser RR, Sarntinoranont M, Morrison PF, Oldfield EH. Convection-enhanced delivery to the central nervous system. J. Neurosurg. 122(3), 697-706 (2015).

28. Mehta AM, Sonabend AM, Bruce JN. Convection-enhanced delivery. Neurotherapeutics 14(2), 358-371 (2017).

29. Singh R, Wang M, Schweitzer ME et al. Volume of distribution and clearance of peptide-based nanofiber after convection-enhanced delivery. J. Neurosurg. 129(1), 10-18 (2018).

30. Liu Q, Shen Y, Chen J et al. Nose-to-brain transport pathways of wheat germ agglutinin conjugated PEG-PLA nanoparticles. Pharm. Res. 29(2), 546-558 (2012).

31. De Lorenzo AJD. The olfactory neuron and the blood-brain barrier. In: Taste and Smell in Vertebrates. Wolstenholme G, Knight J (Eds). Churchhill, London, UK, 151-176 (1970).

32. Gopinath PG, Gopinath G, Kumar TCA. Target site of intranasally sprayed substances and their transport across the nasal mucosa: a new insight into the intransal route of drug-delivery. Curr. Ther. Res. 23(5), 596-607 (1978).

33. Oberdörster G, Sharp Z, Atudorei V et al. Translocation of inhaled ultrafine particles to the brain. Inhal. Toxicol. 16(6-7), 437-445 (2004).

34. Elder A, Gelein R, Silva V et al. Translocation of inhaled ultrafine manganese oxide particles to the central nervous system. Environ. Health Perspect. 114(8), 1172-1178 (2006). 
35. Hopkins LE, Patchin ES, Chiu P-L et al. Nose-to-brain transport of aerosolised quantum dots following acute exposure. Nanotoxicology 8(8), 885-893 (2014).

36. Migliore MM, Vyas TK, Campbell RB, Amiji MM, Waszczak BL. Brain delivery of proteins by the intranasal route of administration: a comparison of cationic liposomes versus aqueous solution formulations. J. Pharm. Sci. 99(4), 1745-1761 (2010).

37. Wang D, Wu Y, Xia J. Review on photoacoustic imaging of the brain using nanoprobes. Neurophotonics 3(1), 010901 (2016).

38. Baddeley D, Bewersdorf J. Biological insight from super-resolution microscopy: what we can learn from localization-based images. Annu. Rev. Biochem. 87, 965-989 (2018).

39. Feiner-Gracia N, Beck M, Pujals $S$ et al. Super-resolution microscopy unveils dynamic heterogeneities in nanoparticle protein corona. Small 13(41), 1701631 (2017).

40. Clemments AM, Botella P, Landry CC. Spatial mapping of protein adsorption on mesoporous silica nanoparticles by stochastic optical reconstruction microscopy. J. Am. Chem. Soc. 139(11), 3978-3981 (2017).

41. Van Der Zwaag D, Vanparijs N, Wijnands S et al. Super resolution imaging of nanoparticles cellular uptake and trafficking. ACS Appl. Mater. Interfaces 8(10), 6391-6399 (2016).

42. Fumagalli G, Mazza D, Christodoulou MS et al. Cyclopamine-paclitaxel-containing nanoparticles: internalization in cells detected by confocal and super-resolution microscopy. ChemPlusChem 80(9), 1380-1383 (2015).

43. Patskovsky S, Bergeron E, Rioux D, Meunier M. Wide-field hyperspectral 3D imaging of functionalized gold nanoparticles targeting cancer cells by reflected light microscopy. J. Biophotonics 8(5), 401-407 (2015).

44. Roth GA, Tahiliani S, Neu-Baker NM, Brenner SA. Hyperspectral microscopy as an analytical tool for nanomaterials. Wiley Interdiscip. Rev. Nanomed. Nanobiotechnol. 7(4), 565-579 (2015).

45. Pena MDPS, Gottipati A, Tahiliani S et al. Hyperspectral imaging of nanoparticles in biological samples: simultaneous visualization and elemental identification. Microsc. Res. Tech. 79(5), 349-358 (2016).

46. Mulik RS, Bing C, Ladouceur-Wodzak M et al. Localized delivery of low-density lipoprotein docosahexaenoic acid nanoparticles to the rat brain using focused ultrasound. Biomaterials 83, 257-268 (2016).

47. Åslund AKO, Berg S, Hak S et al. Nanoparticle delivery to the brain - by focused ultrasound and self-assembled nanoparticle-stabilized microbubbles. J. Control. Rel. 220(Part A), 287-294 (2015).

-• One of the best demonstrations differentiating NP and NP component distribution within and not within brain parenchyma.

48. Yang T, Martin P, Fogarty B et al. Exosome delivered anticancer drugs across the blood-brain barrier for brain cancer therapy in Danio Rerio. Pharm. Res. 32(6), 2003-2014 (2015).

49. Han L, Kong DK, Zheng M-Q et al. Increased nanoparticle delivery to brain tumors by autocatalytic priming for improved treatment and imaging. ACS Nano 10(4), 4209-4218 (2016).

50. Kundu P, Das M, Tripathy K, Sahoo SK. Delivery of dual drug loaded lipid based nanoparticles across the blood-brain barrier impart enhanced neuroprotection in a rotenone induced mouse model of parkinson's disease. ACS Chem. Neurosci. 7(12), 1658-1670 (2016).

51. Ko YT. Nanoparticle-mediated delivery of oligonucleotides to the blood-brain barrier: in vitro and in situ brain perfusion studies on the uptake mechanisms. J. Drug Target. 21(9), 866-873 (2013).

52. Hu X, Yang F, Liao Y, Li L, Zhang L. Cholesterol-PEG comodified poly(N-butyl) cyanoacrylate nanoparticles for brain delivery: in vitro and in vivo evaluations. Drug Deliv. 24(1), 121-132 (2017).

53. Liang J, Gao C, Zhu Y et al. Natural brain penetration enhancer-modified albumin nanoparticles for glioma targeting delivery. ACS Appl. Mater. Interfaces 10(36), 30201-30213 (2018).

54. Tamba BI, Streinu V, Foltea G et al. Tailored surface silica nanoparticles for blood-brain barrier penetration: preparation and in vivo investigation. Arabian J. Chem. 11(6), 981-990 (2018).

55. Yang J-T, Kuo Y-C, Chen IY et al. Protection against neurodegeneration in the hippocampus using sialic acid- and 5-HT-moduline-conjugated lipopolymer nanoparticles. ACS Biomater. Sci. Eng. 5(3), 1311-1320 (2019).

56. Rasmussen K, González M, Kearns P et al. Review of achievements of the OECD Working Party on Manufactured Nanomaterials' Testing and Assessment Programme. From exploratory testing to test guidelines. Regul. Toxicol. Pharmacol. 74, 147-160 (2016).

57. Lin P-C, Lin S, Wang PC, Sridhar R. Techniques for physicochemical characterization of nanomaterials. Biotechnol. Adv. 32(4), 711-726 (2014).

58. Manaia EB, Abuçafy MP, Chiari-Andréo BG et al. Physicochemical characterization of drug nanocarriers. Int. J. Nanomed. 12, 4991-5011 (2017).

59. Agronskaia AV, Valentijn JA, Van Driel LF et al. Integrated fluorescence and transmission electron microscopy. J. Struct. Biol. 164(2), 183-189 (2008).

60. Kempen PJ, Kircher MF, De La Zerda A et al. A correlative optical microscopy and scanning electron microscopy approach to locating nanoparticles in brain tumors. Micron 68, 70-76 (2015).

61. Han S, Raabe M, Hodgson L et al. High-contrast imaging of nanodiamonds in cells by energy filtered and correlative light-electron microscopy: toward a quantitative nanoparticle-cell analysis. Nano Lett. 19(3), 2178-2185 (2019). 
62. Weiss B, Schaefer UF, Zapp J et al. Nanoparticles made of fluorescence-labelled poly(L-lactide-co-glycolide): preparation, stability, and biocompatibility. J. Nanosci. Nanotechnol. 6(9-10), 3048-3056 (2006).

63. Zandanel C, Vauthier C. Characterization of fluorescent poly(isobutylcyanoacrylate) nanoparticles obtained by copolymerization of a fluorescent probe during Redox Radical Emulsion Polymerization (RREP). Eur. J. Pharm. Biopharm. 82(1), 66-75 (2012).

64. Li K, Liu B. Polymer-encapsulated organic nanoparticles for fluorescence and photoacoustic imaging. Chem. Soc. Rev. 43(18), 6570-6597 (2014).

65. Reisch A, Klymchenko AS. Fluorescent polymer nanoparticles based on dyes: seeking brighter tools for bioimaging. Small 12(15), 1968-1992 (2016).

66. Takasato Y, Rapoport SI, Smith QR. An in situ brain perfusion technique to study cerebrovascular transport in the rat. Am. J. Physiol. 247(3 Pt 2), H484-H493 (1984).

67. Triguero D, Buciak J, Pardridge WM. Capillary depletion method for quantification of blood-brain barrier transport of circulating peptides and plasma proteins. J. Neurochem. 54(6), 1882-1888 (1990).

68. Yokel RA. Methods to quantify nanomaterial association with, and distribution across, the blood-brain barrier in vivo. In: Nanotoxicity: Methods and Protocols. Zhang Q (Ed.). Springer, NY, USA, 281-299 (2018).

69. Wohlfart S, Khalansky AS, Gelperina S, Begley D, Kreuter J. Kinetics of transport of doxorubicin bound to nanoparticles across the blood-brain barrier. J. Control. Rel. 154, 103-107 (2011).

70. Kafa H, Wang JT-W, Rubio N et al. The interaction of carbon nanotubes with an in vitro blood-brain barrier model and mouse brain in vivo. Biomaterials 53, 437-452 (2015).

71. Ramalingam P, Ko YT. Enhanced oral delivery of curcumin from n-trimethyl chitosan surface-modified solid lipid nanoparticles: pharmacokinetic and brain distribution evaluations. Pharm. Res. 32(2), 389-402 (2015).

72. Pang Z, Gao H, Chen J et al. Intracellular delivery mechanism and brain delivery kinetics of biodegradable cationic bovine serum albumin-conjugated polymersomes. Int. J. Nanomed. 7, 3421-3432 (2012).

73. Johnsen KB, Bak M, Melander F et al. Modulating the antibody density changes the uptake and transport at the blood-brain barrier of both transferrin receptor-targeted gold nanoparticles and liposomal cargo. J. Control. Rel. 295, 237-249 (2019).

74. Bommana MM, Kirthivasan B, Squillante E. In vivo brain microdialysis to evaluate FITC-dextran encapsulated immunopegylated nanoparticles. Drug Deliv. 19(6), 298-306 (2012).

75. Zhang X, Liu L, Chai G, Zhang X, Li F. Brain pharmacokinetics of neurotoxin-loaded PLA nanoparticles modified with chitosan after intranasal administration in awake rats. Drug Dev. Ind. Pharm. 39(11), 1618-1624 (2013).

76. Liu Z, Okeke CI, Zhang L et al. Mixed polyethylene glycol-modified breviscapine-loaded solid lipid nanoparticles for improved brain bioavailability: preparation, characterization, and in vivo cerebral microdialysis evaluation in adult Sprague Dawley rats. AAPS PharmSciTech 15(2), 483-496 (2014).

77. Zhu J, Zou J, Mu C et al. Intranasal administration of pullulan-based nanoparticles for enhanced delivery of adriamycin into the brain: in vitro and in vivo evaluation. Pharmazie 74(1), 39-46 (2019).

78. Al Zaki A, Hui JZ, Higbee E, Tsourkas A. Biodistribution, clearance, and toxicology of polymeric micelles loaded with 0.9 or $5 \mathrm{~nm}$ gold nanoparticles. J. Biomed. Nanotechnol. 11(10), 1836-1846 (2015).

79. Krauze MT, Noble CO, Kawaguchi T et al. Convection-enhanced delivery of nanoliposomal CPT-11 (irinotecan) and PEGylated liposomal doxorubicin (Doxil) in rodent intracranial brain tumor xenografts. Neuro-Oncol. 9(4), 393-403 (2007).

80. Corem-Salkmon E, Ram Z, Daniels D et al. Convection-enhanced delivery of methotrexate-loaded maghemite nanoparticles. Int. J. Nanomed. 6, 1595-1602 (2011).

81. Noble CO, Krauze MT, Drummond DC et al. Novel nanoliposomal CPT-11 infused by convection-enhanced delivery in intracranial tumors: pharmacology and efficacy. Cancer Res. 66(5), 2801-2806 (2006).

82. Oppong-Damoah A, Zaman RU, D'Souza MJ, Murnane KS. Nanoparticle encapsulation increases the brain penetrance and duration of action of intranasal oxytocin. Horm. Behav. 108, 20-29 (2019).

83. Mackay JA, Deen DF, Szoka FC. Distribution in brain of liposomes after convection enhanced delivery; modulation by particle charge, particle diameter, and presence of steric coating. Brain Res. 1035(2), 139-153 (2005).

84. Saito R, Krauze MT, Noble CO et al. Convection-enhanced delivery of Ls-TPT enables an effective, continuous, low-dose chemotherapy against malignant glioma xenograft model. Neuro-Oncol. 8(3), 205-214 (2006).

85. French JT, Goins B, Saenz M et al. Interventional therapy of head and neck cancer with lipid nanoparticle-carried rhenium 186 radionuclide. J. Vasc. Interv. Radiol. 21(8), 1271-1279 (2010).

86. Weng KC, Hashizume R, Noble CO et al. Convection-enhanced delivery of targeted quantum dot-immunoliposome hybrid nanoparticles to intracranial brain tumor models. Nanomedicine (Lond.) 8(12), 1913-1925 (2013).

87. Sirianni RW, Zheng M-Q, Patel TR et al. Radiolabeling of poly(lactic-co-glycolic acid) (PLGA) nanoparticles with biotinylated F-18 prosthetic groups and imaging of their delivery to the brain with positron emission tomography. Bioconjug. Chem. 25(12), 2157-2165 (2014). 
88. Arshad A, Yang B, Bienemann AS et al. Convection-enhanced delivery of carboplatin PLGA nanoparticles for the treatment of glioblastoma. PLoS ONE 10(7), e0132266 (2015).

89. Chen EM, Quijano AR, Seo Y-E et al. Biodegradable PEG-poly( $\omega$-pentadecalactone-co-p-dioxanone) nanoparticles for enhanced and sustained drug delivery to treat brain tumors. Biomaterials 178, 193-203 (2018).

90. Stephen ZR, Revia RA, Wang K et al. Time-resolved MRI assessment of convection-enhanced delivery by targeted and non-targeted nanoparticles in a human glioblastoma mouse model. Cancer Res. 79(18), 4776-4786 (2019).

91. Stucht D, Danishad KA, Schulze P et al. Highest resolution in vivo human brain MRI using prospective motion correction. PLoS ONE 10(7), e0133921 (2015).

92. IVIS Imaging Systems (2019). www.Perkinelmer.Com/Lab-Solutions/Resources/Docs/Sht_011713c_01_Ivis_Comparison_Table.Pdf

93. Barré FPY, Heeren RMA, Potočnik NO. Mass Spectrometry imaging in nanomedicine: unraveling the potential of MSI for the detection of nanoparticles in neuroscience. Curr. Pharm. Des. 23(13), 1974-1984 (2017).

94. Ries J, Kaplan C, Platonova E, Eghlidi H, Ewers H. A simple, versatile method for GFP-based super-resolution microscopy via nanobodies. Nat. Methods 9(6), 582-584 (2012).

95. Dudok B, Barna L, Ledri M et al. Cell-specific STORM super-resolution imaging reveals nanoscale organization of cannabinoid signaling. Nat. Neurosci. 18(1), 75-86 (2015).

96. Herrmannsdorfer F, Flottman B, Nanguneri S et al. 3D D STORM imaging of fixed brain tissue. Methods Mol. Biol. 1538, 169-184 (2017).

97. Wen C-J, Zhang L-W, Al-Suwayeh SA, Yen T-C, Fang J-Y. Theranostic liposomes loaded with quantum dots and apomorphine for brain targeting and bioimaging. Int. J. Nanomed. 7, 1599-1611 (2012).

98. Singh-Moon RP, Roblyer DM, Bigio IJ, Joshi S. Spatial mapping of drug delivery to brain tissue using hyperspectral spatial frequency-domain imaging. J. Biomed. Opt. 19(9), 96003 (2014).

99. Mitkovski M, Padovan-Neto FE, Raisman-Vozari R et al. Investigations into potential extrasynaptic communication between the dopaminergic and nitrergic systems. Front. Physiol. Membr. Physiol. Biophys. 3(Sept.), 372 (2012).

100. Malatesta M. Transmission electron microscopy for nanomedicine: novel applications for long-established techniques. Eur. J. Histochem. 60(4), 280-284 (2016).

101. Tröster SD, Müller U, Kreuter J. Modification of the body distribution of poly(methyl methacrylate) nanoparticles in rats by coating with surfactants. Int. J. Pharm. 61(1-2), 85-100 (1990).

102. Fundarò A, Cavalli R, Bargoni A et al. Non-stealth and stealth solid lipid nanoparticles (SLN) carrying doxorubicin: pharmacokinetics and tissue distribution after i.v. administration to rats. Pharmacol. Res. 42(4), 337-343 (2000).

103. Gao K, Jiang X. Influence of particle size on transport of methotrexate across blood brain barrier by polysorbate 80-coated polybutylcyanoacrylate nanoparticles. Int. J. Pharm. 310(1-2), 213-219 (2006).

104. Chen Y-S, Hung Y-C, Lin L-W et al. Size-dependent impairment of cognition in mice caused by the injection of gold nanoparticles. Nanotechnol. 21, 485102/485101-485102/485109 (2010).

105. Guerrero S, Araya E, Fiedler JL et al. Improving the brain delivery of gold nanoparticles by conjugation with an amphipathic peptide. Nanomedicine (Lond.) 5, 897-913 (2010).

106. Liu H-L, Hua M-Y, Yang H-W et al. Magnetic resonance monitoring of focused ultrasound/magnetic nanoparticle targeting delivery of therapeutic agents to the brain. Proc. Natl Acad. Sci. USA 107(34), 15205-10- (2010).

107. Tsai Y-M, Chien C-F, Lin L-C, Tsai T-H. Curcumin and its nano-formulation: the kinetics of tissue distribution and blood-brain barrier penetration. Int. J. Pharm. 416(1), 331-338 (2011).

108. Wen C-J, Yen T-C, Al-Suwayeh SA, Chang H-W, Fang J-Y. In vivo real-time fluorescence visualization and brain-targeting mechanisms of lipid nanocarriers with different fatty ester:oil ratios. Nanomedicine (Lond.) 6(9), 1545-1559 (2011).

109. Wen Z, Yan Z, He R et al. Brain targeting and toxicity study of odorranalectin-conjugated nanoparticles following intranasal administration. Drug Deliv. 18(8), 555-561 (2011b).

110. Dziendzikowska K, Gromadzka-Ostrowska J, Lankoff A et al. Time-dependent biodistribution and excretion of silver nanoparticles in male Wistar rats. J. Appl. Toxicol. 32(11), 920-928 (2012).

111. Prades R, Guerrero S, Araya E et al. Delivery of gold nanoparticles to the brain by conjugation with a peptide that recognizes the transferrin receptor. Biomaterials 33(29), 7194-7205 (2012).

112. Martins SM, Sarmento B, Nunes C et al. Brain targeting effect of camptothecin-loaded solid lipid nanoparticles in rat after intravenous administration. Eur. J. Pharm. Biopharm. 85(3PA), 488-502 (2013).

113. Mazza M, Notman R, Anwar J et al. Nanofiber-based delivery of therapeutic peptides to the brain. ACS Nano 7(2), 1016-1026 (2013).

- The timecourse of NP component in the brain compared with blood suggests distribution out of blood, perhaps into brain parenchyma. Imaging results support this suggestion.

114. Chaturvedi M, Kaczmarek L, Molino Y, Sreedhar B, Khrestchatisky M. Tissue inhibitor of matrix metalloproteinases-1 loaded poly(lactic-co-glycolic acid) nanoparticles for delivery across the blood-brain barrier. Int. J. Nanomed. 9, 575-588 (2014). 
115. Chen Y-C, Chiang C-F, Chen L-F et al. Polymersomes conjugated with des-octanoyl ghrelin and folate as a BBB-penetrating cancer cell-targeting delivery system. Biomaterials 35(13), 4066-4081 (2014).

116. Jose S, Sowmya S, Cinu TA et al. Surface modified PLGA nanoparticles for brain targeting of bacoside-A. Eur. J. Pharm. Sci. 63, 29-35 (2014).

117. Joachim E, Kim I-D, Jin Y et al. Gelatin nanoparticles enhance the neuroprotective effects of intranasally administered osteopontin in rat ischemic stroke model. Drug Del. Trans. Res. 4(5-6), 395-399 (2014).

118. Shilo M, Motiei M, Hana P, Popovtzer R. Transport of nanoparticles through the blood-brain barrier for imaging and therapeutic applications. Nanoscale 6(4), 2146-2152 (2014).

119. Wang B, Lv L, Wang Z et al. Nanoparticles functionalized with Pep-1 as potential glioma targeting delivery system via interleukin 13 receptor $\alpha 2$-mediated endocytosis. Biomaterials 35(22), 5897-5907 (2014).

120. Wang JTW, Fabbro C, Venturelli E et al. The relationship between the diameter of chemically-functionalized multi-walled carbon nanotubes and their organ biodistribution profiles in vivo. Biomaterials 35(35), 9517-9528 (2014).

121. Yang L, Kuang H, Zhang W et al. Size dependent biodistribution and toxicokinetics of iron oxide magnetic nanoparticles in mice. Nanoscale 7(2), 625-636 (2015).

122. Yadav S, Gattacceca F, Panicucci R, Amiji MM. Comparative biodistribution and pharmacokinetic analysis of cyclosporine-A in the brain upon intranasal or intravenous administration in an oil-in-water nanoemulsion formulation. Mol. Pharm. 12(5), 1523-1533 (2015).

123. Joo J, Kwon EJ, Kang J et al. Porous silicon-graphene oxide core-shell nanoparticles for targeted delivery of siRNA to the injured brain. Nanoscale Horiz. 1(5), 407-414 (2016).

124. Zhang C, Liu Q, Shao X, Qian Y, Zhang Q. Phage-displayed peptide-conjugated biodegradable nanoparticles enhanced brain drug delivery. Mater. Lett. 167, 213-217 (2016).

125. Ruan S, Hu C, Tang X et al. Increased gold nanoparticle retention in brain tumors by in situ enzyme-induced aggregation. ACS Nano 10(11), 10086-10098 (2016).

126. Shah B, Khunt D, Misra M, Padh H. Application of Box-Behnken design for optimization and development of quetiapine fumarate loaded chitosan nanoparticles for brain delivery via intranasal route. Int. J. Biol. Macromol. 89, 206-218 (2016).

- Brain and blood timecourses that suggest NP component in bulk brain can be attributed to its presence in blood within the brain.

127. Belhadj Z, Ying M, Wei X et al. Multifunctional targeted liposomal drug delivery for efficient glioblastoma treatment. Oncotarget 8(40), 66889-66900 (2017).

128. Betzer O, Shilo M, Opochinsky R et al. The effect of nanoparticle size on the ability to cross the blood-brain barrier: an in vivo study. Nanomedicine (Lond.) 12(13), 1533-1546 (2017).

129. Bouchoucha M, Béliveau É, Kleitz F, Calon F, Fortin M-A. Antibody-conjugated mesoporous silica nanoparticles for brain microvessel endothelial cell targeting. J. Mater. Chem. B 5(37), 7721-7735 (2017).

130. Ghadiri M, Vasheghani-Farahani E, Atyabi $\mathrm{F}$ et al. Transferrin-conjugated magnetic dextran-spermine nanoparticles for targeted drug transport across blood-brain barrier. J. Biomed. Mater. Res. A 105(10), 2851-2864 (2017).

131. Velasco-Aguirre C, Morales-Zavala F, Salas-Huenuleo E et al. Improving gold nanorod delivery to the central nervous system by conjugation to the shuttle Angiopep-2. Nanomedicine (Lond.) 12(20), 2503-2517 (2017).

132. Ishak RaH, Mostafa NM, Kamel AO. Stealth lipid polymer hybrid nanoparticles loaded with rutin for effective brain delivery - comparative study with the gold standard (Tween 80): optimization, characterization and biodistribution. Drug Deliv. 24(1), 1874-1890 (2017).

133. Kumar P, Sharma G, Kumar R et al. Stearic acid based, systematically designed oral lipid nanoparticles for enhanced brain delivery of dimethyl fumarate. Nanomedicine (Lond.) 12(23), 2607-2621 (2017).

134. Ammar HO, Ghorab MM, Mahmoud AA, Higazy IM. Lamotrigine loaded poly- $\varepsilon$-(D,L-lactide-co-caprolactone) nanoparticles as brain delivery system. Eur. J. Pharm. Sci. 115, 77-87 (2018).

135. Chan TG, Morse SV, Copping MJ, Choi JJ, Vilar R. Targeted delivery of DNA-Au nanoparticles across the blood-brain barrier using focused ultrasound. ChemMedChem 13(13), 1311-1314 (2018).

136. Dutta L, Mukherjee B, Chakraborty T et al. Lipid-based nanocarrier efficiently delivers highly water soluble drug across the blood-brain barrier into brain. Drug Deliv. 25(1), 504-516 (2018).

137. Fernandes J, Ghate MV, Basu Mallik S, Lewis SA. Amino acid conjugated chitosan nanoparticles for the brain targeting of a model dipeptidyl peptidase-4 inhibitor. Int. J. Pharm. 547(1-2), 563-571 (2018).

138. Li HY, Zhang B, Chan PS et al. Convergent synthesis and characterization of fatty acid-conjugated poly(ethylene glycol)-block-poly(epsilon-caprolactone) nanoparticles for improved drug delivery to the brain. Eur. Polym. J. 98, 394-401 (2018).

139. Graverini G, Piazzini V, Landucci E et al. Solid lipid nanoparticles for delivery of andrographolide across the blood-brain barrier: in vitro and in vivo evaluation. Colloids Surf. B 161, 302-313 (2018).

140. Najafabadi RE, Kazemipour N, Esmaeili A, Beheshti S, Nazifi S. Using superparamagnetic iron oxide nanoparticles to enhance bioavailability of quercetin in the intact rat brain. BMC Pharmacol. Toxicol. 19(1), 59 (2018). 
141. Pandey PK, Sharma AK, Rani S et al. MCM-41 nanoparticles for brain delivery: better choline-esterase and amyloid formation inhibition with improved kinetics. ACS Biomater. Sci. Eng. 4(8), 2860-2869 (2018).

142. Chen Y, Xu C, Yu B, Fan H, Hu W. Efficient cholera toxin B subunit-based nanoparticles with MRI capability for drug delivery to the brain following intranasal administration. Macromol. Biosci. 19(2), e1800340 (2019).

143. Ha S-W, Cho A-S, Kim TY et al. Ultrasound-sensitizing nanoparticle complex for overcoming the blood-brain barrier: an effective drug delivery system. Int. J. Nanomed. 14, 3743-3752 (2019).

144. Israel LL, Braubach O, Galstyan A et al. A combination of tri-Leucine and angiopep-2 drives a polyanionic polymalic acid nanodrug platform across the blood-brain barrier. ACS Nano 13(2), 1253-1271 (2019).

145. Zhang T, Lip H, He C et al. Multitargeted nanoparticles deliver synergistic drugs across the blood-brain barrier to brain metastases of triple negative breast cancer cells and tumor-associated macrophages. Adv. Healthcare Mat. 8(18), e1900543 (2019). 